\title{
Tensile Deformation and Fracture Properties of a 14YWT
}

\section{Nanostructured Ferritic Alloy}

\author{
M. E. Alam ${ }^{a}{ }^{*}$, S. Pal ${ }^{\text {a) }}$, K. Fields ${ }^{\text {a) }}$, S. Maloy ${ }^{\text {b) }}$, D. T. Hoelzer ${ }^{\text {() }}$, G. R. Odette ${ }^{\text {a) }}$ \\ a) Materials Department, University of California, Santa Barbara, CA 93106, USA \\ b) Los Alamos National Laboratory, Los Alamos, NM 87545, USA \\ c) Materials Science and Technology Division, Oak Ridge National Laboratory, Oak
}

Ridge, TN 37830, USA

"Corresponding author. Tel.: +1 (805) 893-3848; fax +1 (805) 893-8651

E-mail address: alam@engineering.ucsb.edu (M. E. Alam)

\begin{abstract}
A new larger heat of a 14YWT nanostructured ferritic alloy (NFA), FCRD NFA-1, was synthesized by ball milling $\mathrm{FeO}$ and argon atomized Fe-14Cr-3W-0.4Ti-0.2Y (wt.\%) powders, followed by hot extrusion, annealing and cross rolling to produce a $12.5 \mathrm{~mm}$ thick plate. NFA-1 contains a bimodal size distribution of pancake-shaped, mostly very fine scale, grains. The as-processed plate also contains a large population of microcracks running parallel to its broad surfaces. The small grains and large concentration of Y-Ti-O nano-oxides (NOs) result in high strength up to $800^{\circ} \mathrm{C}$. The uniform and total elongations range from $\approx 1$ to $8 \%$, and $\approx 10$ to $24 \%$, respectively. The strength decreases more rapidly above $\approx 400^{\circ} \mathrm{C}$ and transitions to largely viscoplastic creep by $\approx 600^{\circ} \mathrm{C}$. While the local fracture mechanism is ductile-dimple microvoid nucleation, growth and coalescence, perhaps the most notable feature of tensile deformation behavior of NFA-1 is the occurrence of periodic delamination, manifested as fissures on the fracture surfaces.
\end{abstract}


Keywords: Nanostructured ferritic alloy; Nano oxide; Delamination; Tensile properties; Fractography.

\section{Introduction}

The success of advanced nuclear fission and future fusion energy sources depends on the development of new, high performance structural materials that can sustain extended component lifetimes in extremely hostile irradiation environments. Nanostructured ferritic alloys (NFAs), which are leading candidates for these applications, have high tensile, fatigue and creep strengths over a wide range of temperatures, as well as outstanding irradiation tolerance and unique thermal stability up to $900^{\circ} \mathrm{C}$ [1-3]. The outstanding properties of $12-14 \% \mathrm{Cr}$ NFAs are derived from the presence of submicron ( $500 \mathrm{~nm})$ grains, high dislocation densities $\left(0.5-2 \times 10^{15} / \mathrm{m}^{2}\right)$ and an ultrahigh population $\left(10^{23}-10^{24} / \mathrm{m}^{3}\right)$ of nanometer scale $(2-4 \mathrm{~nm}) \mathrm{Y}$-Ti-O rich multifunctional nano-oxides (NOs). The NOs retard dislocation climb and glide, stabilize grain and dislocation structures, and trap helium in fine bubbles that retard swelling and grain boundary embrittlement [1-7]. Unlike many very high strength materials, NFAs often exhibit significant ductility and reasonable fracture toughness in standard test orientations [8-12].

NFAs are typically described by a number designating their $\mathrm{Cr}$ content followed by YWT indicating their primary micro-alloying elements, Y, W and Ti. A new 14YWT NFA, named FCRD NFA-1, with a nominal composition of Fe-14Cr-3W-0.4Ti-0.2Y (wt.\%), was developed in a collaboration between the University of California, Santa Barbara (UCSB), Los Alamos National Laboratory (LANL) and Oak Ridge National Laboratory (ORNL). The objective was to achieve a good combination of strength, 
ductility, toughness and irradiation tolerance in a larger heat of NFA. Processing NFA-1 involved an alternative path that involved including $\mathrm{Y}$ in the melt prior to gas atomization and rapid solidification. Many small lab heats of precursor NFA, with different processing and compositional variants, were first explored to identify the best practice path $[3,10,13-16]$. This culminated in the final production of an extruded and crossrolled heat known as 14YWT-PM2 (PM2) [17]. NFA-1 is larger-scale heat (55 kg), processed by the same route as PM2, in the form of a $12.5 \mathrm{~mm}$ thick plate [18].

Characterization of NFA-1 NOs, dislocations and grain structures are described elsewhere [18]. Here we focus on the basic tensile deformation and fracture properties of NFA-1. Companion studies of fracture toughness, texturing and the underlying micromechanics of deformation and fracture are reported elsewhere [19, 20]. Unlike most previous results, a special effort is made here to characterize the effects of orientation of the test specimens with respect to the plate geometry and primary deformation processing directions. Further, the combined effect of prior plate microcracking and subsequent delamination during testing, are systematically explored for the first time. Tensile tests were carried out in air from room temperature to $800^{\circ} \mathrm{C}$. Scanning electron microscopy (SEM) was used to examine grain size, coarser oxide features, microcracks, fracture surfaces, and the deformation patterns at the point of material separation. Electron backscatter diffraction (EBSD) was used to characterize grain texturing and grain boundaries, while limited transmission electron microscopy (TEM) was used to identify the micromechanisms of microcrack formation. 


\section{Materials and Methods}

\subsection{Processing NFA-1}

NFAs are typically processed by ball milling rapidly solidified Fe-Cr-Ti-W and $\mathrm{Y}_{2} \mathrm{O}_{3}$ powders to mechanically alloy the $\mathrm{Y}$ and $\mathrm{O}$ into solid solution. The powders are then consolidated by high temperature hot isostatic pressing or extrusion [1,5]. The NOs precipitate during hot consolidation, at sizes $(\mathrm{d})$ and number densities $(\mathrm{N})$ that depend on alloy composition and temperature [14]. The consolidated NFA is then typically deformation processed, both to achieve better properties and a final near net shape. In the case of NFA-1, Y was included in the melt prior to gas atomization and rapid solidification. This was intended to explore the possibility of minimizing the ball-milling step and to produce more uniform distributions of NOs. ATI Powder Metals (Pittsburgh, PA) provided the atomized Fe-14Cr-3W-0.4Ti-0.2Y powders with a controlled range of $\mathrm{O}$ contents. However, the $\mathrm{Y}$ was found to be phase-separated after atomization, hence, the powders required extensive ball milling for $40 \mathrm{~h}$ that was carried out by $\mathrm{Zoz} \mathrm{GmbH}$ (Wenden, Germany) in a CM100b attritor mill, with a ball mass-to-charge ratio of 10:1 and ball size of $5 \mathrm{~mm}$. After ball milling the $\mathrm{Y}$ was uniformly distributed. The final Zoz milling was carried out on a low oxygen powder. In order to optimize the composition, the atomized powders were milled with 10 mesh $\mathrm{FeO}$ powders to yield $\approx 0.125 \mathrm{wt} . \% \mathrm{O}$. The powders were then sealed in a $100 \mathrm{~mm}$ diameter mild steel can, degassed at $400^{\circ} \mathrm{C}$, and hot extruded at $850^{\circ} \mathrm{C}$ through a $64 \mathrm{~mm} \times 30 \mathrm{~mm}$ rectangular die. The extruded bar was annealed for 1 hour and then hot cross-rolled to an $\approx 50 \%$ thickness reduction, both at $1000^{\circ} \mathrm{C}$, to form an $\approx 15 \mathrm{~mm}$ thick section including the can, containing the $12.5 \mathrm{~mm}$ NFA-1 plate. 


\subsection{Characterization of the grain structure and coarse scale microstructures in NFA-1}

The grain structure of the NFA-1 was evaluated in the three plate sections, designated as LT (face), LS (side, parallel to the rolling direction) and TS (front, perpendicular to the rolling direction), as illustrated in Figure 1. The characterization toolkit primarily included: a) SEM on an FEI x30, equipped with energy dispersive spectroscopy (EDS); b) SEM on a dual beam Scanning Electron Microscope/Focused Ion Beam (SEM/FIB) FEI Helios 600; and, c) electron backscatter diffraction (EBSD) on an FEI Quanta 400F SEM. Typical sample preparation steps included 1500 grit grinding and polishing with $20 \mathrm{~nm}$ colloidal silica. Some polished samples were etched with Kroll's reagent (92\% distilled water, $6 \%$ nitric acid, and 2\% hydrofluoric acid). The longest (l) and shortest (s) dimensions of minimum 500 individual grains were tabulated from the SEM and SEM/FIB micrographs using 'ImageJ64' software. The nominal grain size was taken as $\mathrm{d}=(1+\mathrm{s}) / 2$ and the aspect ratio as $\mathrm{r}=1 / \mathrm{s}$. EBSD (parameters: voltage: $20 \mathrm{KeV}$, spot size: 4 , step size: $0.05 \mu \mathrm{m}$ and working distance: $10 \mathrm{~mm}$ ) was used to characterize the textures induced by hot extrusion and cross-rolling. SEM and TEM, both equipped with EDS, were used to characterize the coarser-scale precipitates and microcracks [20-21]. SEM was also used extensively to characterize the fracture surfaces, tensile deformation, cracking patterns, and delamination.

\subsection{Mechanical Testing}

Vickers microhardness measurements $\left(\mathrm{H}_{\mathrm{v}}\right)$ were performed on polished surfaces of the various plate sections at a 500g load using a LECO M-400A semi-automated testing 
instrument. A total of 10 to 15 indents were made in all cases in accordance with ASTM test standard E384-11e1 [22].

Tensile tests were performed on dog bone shaped and sub-sized flat specimens with a nominal gauge section of $5.0 \times 1.2 \times 0.5 \mathrm{~mm}^{3}$ [23] in four different orientations designated as LT, TL, LS and TS, as illustrated in Figure 1. Here the first letter designates the tensile axis orientation parallel (L) or transverse $(\mathrm{T})$ with respect to the extrusion direction; while the second letter designates the plane of the plate that the specimen was extracted from - either the broad face (L or T) or short plate thickness (S) front or side. Thus there are 4 specimen orientations designated as LT and TL (for the face), and LS and TS (for the side). The tensile specimens were cleaned with1500 grit paper to remove surface oxidation and damage caused by the electrical discharge machining (EDM). A MTS 810 servo-hydraulic universal testing machine equipped with a clam shell furnace was used to conduct the tests in air at temperatures ranging from ambient $\left(\approx 22^{\circ} \mathrm{C}\right)$ to $800^{\circ} \mathrm{C}$. Note, the TS orientation was tested only at ambient temperature and $600^{\circ} \mathrm{C}$. The specimens were heated to the target temperature and held for 10 minutes before loading at a displacement rate of $0.30 \mathrm{~mm} / \mathrm{min}$, or a strain rate $\approx 10^{-3} / \mathrm{s}$. A high temperature extensometer, with ceramic arms extending into the furnace, was used to measure grip-togrip displacement. Tensile properties were generally determined in accordance with ASTM test standard E8M-13 [24].

\section{Results and Discussion}

\subsection{Microstructural characterization}

The length scale of the grains and their distribution from different sections (i.e. LT - face, LS - side and TS - front) of the extruded and cross-rolled NFA-1 plate are shown in Tables 1 and 2 and Fig. 2. Figures $2 \mathrm{a}$ and $\mathrm{b}$ show the low magnification SEM, and high 
magnification SEM/FIB images, respectively, of the as-fabricated and pre-test NFA-1 for different planes. The plate faces (LT) are crack-free, with nearly uniform, equiaxed, ultrafine grains (see Table 1). In contrast, the side (LS), and front (TS) sections reveal a large number of microcracks on planes parallel to the plate faces and normal to the short thickness direction. The corresponding grains are pancake-shaped and elongated in the extrusion (LS) and cross-rolling (TS) directions. A bimodal grain size distribution (most are in sub-micron range, others are in micron size range with a small number of grains larger than $10 \mu \mathrm{m}$ ) is also observed (see Table 2 and Fig. 2c). The pancake-shaped grain aspect ratio $(\mathrm{GAR})$ varies from $\approx 2$ to 16 ; the GAR distribution is shown in Fig. $2 \mathrm{~d}$. The fraction of submicron grains is $\approx 80 \%$, representing $\approx 60 \%$ area fraction (see Table 2 ). A through-thickness grain size variation is also observed, with thinner grains found near plate faces and relatively thicker grains in the middle. Most as-fabricated NFAs exhibit bimodal grain size distributions, especially at higher processing temperatures. In some cases large grains can indicate a low number density of NOs. In this alloy, however, the $\mathrm{Y}$ is uniformly distributed, likely due to inclusion during the atomization step, and high number densities of NOs are observed in both the nano- and micron-sized grains. The precursor alloys to NFA-1 have also shown this behavior and large grains with NOs have also been observed by other research groups [25].

Coarse Ti- and Y-rich oxides stringers are also observed (Fig. 2b). Examination of 150 to 270 oxides showed that they ranged in size from $\approx 10 \mathrm{~nm}$ to $260 \mathrm{~nm}$, averaging $\approx$ $60 \mathrm{~nm}$. These coarser oxides are predominantly located at or near prior particle grain boundaries (Fig. 2b). Such features are common in NFA/ODS alloys [26]. Fig. 2 also shows the presence of microcracks running normal to the plate thickness direction in both the side (LS) and front (TS) plate views. The average opening, at the presumed initiation point roughly at the crack center, is $\approx 250 \mathrm{~nm}$. The crack separation distance in the short thickness direction is $\approx 16 \mu \mathrm{m}$. The crack lengths range from 2 to $105 \mu \mathrm{m}$ averaging $\approx$ $10 \mu \mathrm{m}$ (side section) to $15 \mu \mathrm{m}$ (front section). Detailed descriptions of the statistics of the coarser precipitates and cracks are reported elsewhere [21]. 
Figure 3a shows an EBSD inverse pole figure (IPF) map for a section of the LS (side) surface. The map is color-coded to show the grain orientation texturing in the extrusion direction. As expected, most of the grains have a near $<110>$-fiber texture in the extrusion direction. This texturing is also shown in the IPF intensity projection in the bottom right insert of Fig. 3a. The EBSD map also shows one large and one small crack parallel to the extrusion direction, although they may be linked below the surface.

The texturing is accompanied by the development of $\{001\}$ planes normal to the thickness direction. Notably the resulting $\{100\}<011>$ texture represents the most brittle cleavage system in BCC Fe. The $\{100\}$ planes are formed by $\{001\}<001>$ sessile dislocations that create low-angle subgrain boundaries during the initial stages of deformation [20]. Further deformation results in dislocation pile-ups at these subgrain boundaries, creating local stress concentrations and opening displacements that form microcracks on the brittle $\{100\}<110>$ cleavage system (see Fig. 3b). Microcrack propagation is also partly driven by residual stresses that develop during deformation. The detailed mechanisms of texturing and microcrack formation in the NFA-1 plate are discussed elsewhere [20].

\subsection{YWT Strength}

Vickers microhardness $\left(\mathrm{H}_{\mathrm{v}}\right)$ data for NFA-1 is summarized in Table 1. The $\mathrm{H}_{\mathrm{v}}$ averages $376 \pm 18,368 \pm 25$ and $352 \pm 39\left(\mathrm{~kg} / \mathrm{mm}^{2}\right)$ on the plate face, side and front, respectively. The differences, of up to $\sim 6 \%$, are probably not statistically significant. However, the higher standard deviation and lower value of $\mathrm{H}_{\mathrm{v}}$ for the plate front and side is likely due to delamination, which is discussed below. 
Engineering stress-strain or $\mathrm{s}(\mathrm{e})$ curves for the various orientations over a wide range of temperatures are shown in Fig. 4. The average values of the engineering yield $\left(\mathrm{s}_{\mathrm{y}}\right)$ and ultimate $\left(\mathrm{s}_{\mathrm{u}}\right)$ stresses are plotted in Figs. 5a and b, respectively, while the corresponding uniform $\left(e_{u}\right)$ and total $\left(e_{t}\right)$ elongations are shown in Figs. 5c and d, respectively. Table 3 summarizes the average and standard deviations of the tensile properties as a function of temperature and orientation. Note $\mathrm{s}_{\mathrm{y}}$ was determined at the standard nominal $0.2 \%$ offset. Note the differences in $\mathrm{s}(\mathrm{e})$ in the elastic regime are due to temperature-dependent compliance of the specimen and fixture coupling and the initial low load displacements. Figure 6 plots the true stress $(\sigma)$ versus true plastic strain $(\varepsilon)$ curves starting at the nominal $0.2 \%$ offset.

The LT orientation at ambient temperature (AT) exhibits the highest $\mathrm{s}_{\mathrm{y}} \approx 1144 \pm 21$ MPa and $\mathrm{s}_{\mathrm{u}} \approx 1253 \pm 25 \mathrm{MPa}$, accompanied by $\mathrm{e}_{\mathrm{u}} \approx 5.0 \pm 1.5 \%$ and $\mathrm{e}_{\mathrm{t}} \approx 10.6 \pm 2.0 \%$, respectively. The TL orientation generally showed similar strength and ductility. However, the $\mathrm{s}_{\mathrm{y}}$ and $\mathrm{s}_{\mathrm{u}}$ in the LS and TS orientations are slightly lower $(\approx 10 \%)$, while their corresponding $e_{t}$ values are much larger. These differences arise from a combination of texturing, varying grain dimensions and the presence of microcracks and delamination.

As illustrated in Fig. 7a, the LT and TL orientations delaminate, forming splits in the dog bone coupon specimen thickness dimension, propagating parallel to the gauge section width. In the case of the LS and TS orientations multiple delaminations split the width of the gauge section, propagating parallel to the thickness dimension as seen in Figs. $7 \mathrm{~b}$ and d. One effect of the $90^{\circ}$ delamination LT/TL and LS/TS rotation is to lower the lateral stresses, perhaps reducing slightly any triaxial constraint effects. Indeed the s(e) curves in Fig. 4b show possible reductions in the necking constraint in the width 
direction. Figs. 7e and $f$ show a schematic of the microcracks in the two cases. The higher magnification SEM images of fracture surface in the plate face orientation (LT or TL) show large flat-bottomed features, separated by shear lips (Fig. 7g). In contrast, Fig. 7h shows more classical, fine scale ductile-dimple fracture surfaces. The scale of the damage is related to the geometry of the microcracks and specimen width versus thickness. When the microcrack planes are parallel to the gauge section width (LT - broad faces) the scale of damage appears coarser, while the corresponding scale appears finer when the microcracks are parallel to the gauge section thickness (LS or TS - thin faces).

Thus, while the $\mathrm{s}(\mathrm{e})$ curves are primarily controlled by the actual intrinsic material properties of NFA-1, pre-existing microcrack damage and extrinsic factors, like the dog bone coupon tensile specimen geometry, also play a role. Better understanding of how the mix of texturing, damage and extrinsic factors govern tensile deformation of NFA-1 will be investigated in future studies. These studies will be based on finite element simulations, which we routinely use to extract post-necking true $\sigma(\varepsilon)$ constitutive laws $[9$, 27] from tensile test $\mathrm{s}(\mathrm{e})$ data. The future simulations will treat all of the extrinsic factors noted above. However, further discussion of this complex topic is beyond the scope of this paper.

As is common with NFAs and other steels, the $s_{y}$ and $s_{u}$ decrease relatively slowly between ambient temperature and $\approx 400^{\circ} \mathrm{C}$. This is primarily due to the corresponding decrease in the shear modulus $[1,28,29]$. The strength of NFA-1 is controlled by contributions from: (a) Hall-Petch grain boundary strengthening; (b) dislocation pinning by NOs; (c) network dislocation and subgrain structures; and, (d) solid solution matrix hardening $[1,5,26,30]$. The $\mathrm{s}_{\mathrm{y}}$ and $\mathrm{s}_{\mathrm{u}}$ decrease more rapidly above $500^{\circ} \mathrm{C}$ due to a variety 
of thermally activated processes, including dislocation bypass mechanisms associated with de-pinning from the NOs. Above $600^{\circ} \mathrm{C}$ deformation is dominated by viscoplastic creep, even at relatively high strain rates $[1,29-31]$. Creep is indicated by the almost constant true $\sigma$ seen in the post-transient $\sigma(\varepsilon)$ curves in Fig. 6. In the creep regime, the stress at an imposed strain rate $\left(\varepsilon^{\prime}\right)$ and given temperature is governed by a threshold stress $\left(\sigma_{t}\right)$ power law dislocation mechanisms as $[5,32]$

$$
\varepsilon^{\prime}=\operatorname{Cexp}\left(-Q_{c} / R T\right)\left(\sigma-\sigma_{t}\right)^{n} .
$$

Here $Q_{c}$ is the creep activation energy. The $\sigma_{t}$ is a significant fraction of the dislocation obstacle-strengthening component of the static $\sigma_{\mathrm{y}}$. A more detailed discussions of NFA creep properties and processes can be found elsewhere $[1,5,33]$ and will be described for NFA-1 in future publications. Again this paper focuses on nominal strain rate $\left(\approx 10^{-3}\right)$ quasi-static tensile properties.

In spite of the strength decrease above $400^{\circ} \mathrm{C}, \mathrm{NFA}-1$ remains strong at higher temperatures, with $\mathrm{s}_{\mathrm{y}}$ and $\mathrm{s}_{\mathrm{u}}$ of $584 \pm 35 \mathrm{MPa}$ and $630 \pm 35 \mathrm{MPa}$ at $600^{\circ} \mathrm{C}$ and $251 \pm 6$ and $278 \pm 1 \mathrm{MPa}$ at $800^{\circ} \mathrm{C}$, respectively (Table 3 and Fig. 5). Notably, NFA-1 retains $\approx$ $22 \%$ of its ambient temperature strength up to $\sim 2 / 3 \mathrm{~T}_{\mathrm{m}}$, hence qualifies as a ferritic superalloy [1].

Figure 8 compares the $\mathrm{s}_{\mathrm{y}}$ of NFA, ODS and RAFM steels at different temperatures for the LT orientation $[1,4,5,10,11,13,17,28,29,34-35]$. The $\mathrm{s}_{\mathrm{y}}$ for NFA-1 falls roughly in the middle of the strength band for the broad class of NFA representing a wide range of deformation-heat treatment conditions. It is noted that a series of earlier SM plates produced at ORNL range from slightly stronger to much stronger than NFA-1. A Japanese 12WYT also shows higher strength than NFA-1. 
Along with high $\mathrm{s}_{\mathrm{y}}$ and $\mathrm{s}_{\mathrm{u}}$, NFA-1 maintains good tensile ductility over a wide range of temperature, as summarized in Table 3 and Fig. 5. The $\mathrm{e}_{\mathrm{u}}$ is highly anisotropic, generally being highest in the LS orientation, where it ranges from $\approx 1.7$ to $8.1 \pm 0.1 \%$ with a minimum at $600^{\circ} \mathrm{C}$. The $\mathrm{e}_{\mathrm{u}}$ is lowest in the TL orientation, with a minimum at $700^{\circ} \mathrm{C}$ of $0.7 \%$ and a maximum of $4.4 \%$ at $800^{\circ} \mathrm{C}$. A generally similar pattern is observed in the $\mathrm{e}_{\mathrm{t}}$, although the minimum occurs at $400^{\circ} \mathrm{C}$ in this case, and the total strain varies less with temperature, ranging from a minimum of $8.0 \%$ ( $\mathrm{TL}$ at $400^{\circ} \mathrm{C}$ ) to the maximum of $24 \%$ (LS at $\left.800^{\circ} \mathrm{C}\right)$.

\subsection{Tensile fracture deformation, cracking and fracture surface observations}

The room temperature tensile fracture surfaces shown in Fig. 7 reveal different morphologies for LT and TL versus LS and TS orientations. In all cases, the fracture surfaces are dominated by the delamination. As seen in Fig. 7a, one deep delamination crack forms in the middle of the gauge section thickness in the LT and TL orientations, along with some smaller cracks that are observed on the TL fracture surface. A profile gauge section view in Fig. 7c shows that the fracture surface is flat and is associated with only a modest reduction in width. However, both the LT and TL orientations thin extensively in the thickness direction forming two approximately knife-edge-type features surrounding the mid-section out-of-plane delamination. Together these deformation patterns yield a significant reduction in area $(\mathrm{RA})$ of $\approx 52 \pm 2 \%$. In contrast, as seen in Figs. $7 b$ and d, multiple delamination cracks are observed that split the width of the LS and TS specimens. In this case, necking occurs in both the thickness and width directions, leading to a larger RA of $74 \pm 13 \%$. Qualitatively, the reduction in strength and increase in ductility correlates with the number and orientation of the delaminations. 
This correlation could be due to relaxation of a multi-axial stress state, although it is difficult to understand in the context of a uniaxial loading prior to necking. Thus, as noted previously, more detailed finite element simulations of the tensile test are needed.

Further discussion of deformation and fracture mechanisms will focus on LT and LS since they show similar behavior to their respective TL and TS counterparts. Fig. 9 shows the fracture surfaces and profiles for tests at $200^{\circ} \mathrm{C}$. The results are generally very similar to those at ambient temperature, except for the notable absence of major delamination. Both $e_{u}$ and $e_{t}$ decrease when increasing from ambient temperature to $200^{\circ} \mathrm{C}$, with a RA of $\approx 56 \pm 2 \%$ for $\mathrm{LT}$ and $57 \%$ for LS. Note, the RA at $200^{\circ} \mathrm{C}$ in all the orientations are quite similar in the absence of delamination.

Fig. 10 shows the fracture characteristics of LT and LS at $400{ }^{\circ} \mathrm{C}$. The LT orientation again behaves in a very similar manner to that at lower temperatures, again with no sign of any delamination. Fracture in the LS orientation occurs by double shear, as shown in the profile view, along with a single shallow out-of-plane arrested crack. Necking occurs in both the thickness and width directions, resulting in $\approx 47 \%$ RA. The fracture surfaces are similar to those at lower temperature in both cases. The $e_{t}$ is minimum at $400^{\circ} \mathrm{C}$, and again higher in the LS orientation. In contrast $\mathrm{e}_{\mathrm{u}}$ is minimum at $\approx 700^{\circ} \mathrm{C}$. The observed temperature trend marks the transition to viscoplastic creep, starting above $400^{\circ} \mathrm{C}$. There is a generally similar $e_{u}$ and $e_{t}$ in both orientations, and the differences are smaller for $e_{u}$.

Figure 11 shows the fractography results for tests at $600^{\circ} \mathrm{C}$. No delamination is observed and necking occurs in both directions, with up to $\approx 62 \% \mathrm{RA}$. The fracture surfaces again appear to be similar to those at lower temperatures. Side surface cracking normal to the loading direction near the fracture surface is still observed especially in the 
LS orientation. Note the side surface cracking evolves from being parallel to the loading direction at RT, a mix of $45^{\circ}$ and normal cracks at $200-400^{\circ} \mathrm{C}$, and normal at or above $600^{\circ} \mathrm{C}$. The $\mathrm{e}_{\mathrm{u}}$ is near minimum at $600^{\circ} \mathrm{C}$.

The specimens are too oxidized to clearly observe the fracture surfaces in detail at $800^{\circ} \mathrm{C}$. However, overall observations show that there is little necking in the tertiary creep regime, but the substantial $\mathrm{e}_{\mathrm{u}}$ and $\mathrm{e}_{\mathrm{t}}$ ductility is due to the extensive plastic strain in the minimum creep regime. The oxidized fracture surface appears to show a mix of smaller and larger dimple features. The sidewalls of the larger features are filled with smaller dimples (Fig. 12e and f inserts).

\section{Summary and Conclusions}

A summary of the conclusions can be drawn from our tensile test deformation and fracture study of 14YWT NFA-1:

1. Deformation processing produces a bimodal distribution of pancake-shaped grains that are nearly equiaxed when observed on the plate surface and flattened and elongated as seen in the side sections. Small sub- $\mu \mathrm{m}$ grains are dominant, but represent only $\approx 60 \%$ of the grain area fraction.

2. A large population of microcracks form on planes parallel to the broad plate surfaces during extrusion and cross rolling. A more detailed description of the micro cracks and their formation mechanisms are reported elsewhere [20].

3. The microcracks lead to extensive, geometrically mediated delamination during tensile testing at lower temperatures.

4. NFA-1 is a very strong alloy. The average ambient temperature NFA-1 microhardness ranges from 352 to $376 \mathrm{~kg} / \mathrm{mm}^{2}$ on the various plate faces. The ambient temperature $\mathrm{s}_{\mathrm{y}}$ 
and $\mathrm{s}_{\mathrm{u}}$ range from 966 to $1144 \mathrm{MPa}$ and 1053 to $1253 \mathrm{MPa}$, respectfully. The absolute strength difference decreases with increasing temperature.

5. The tensile ductility parameters $\left(e_{u}, e_{t}\right.$ and RA) are much more anisotropic and temperature dependent with a minimum in $\mathrm{e}_{\mathrm{u}}$ at $\approx 700^{\circ} \mathrm{C}$ and in $\mathrm{e}_{\mathrm{t}}$ at $\approx 400^{\circ} \mathrm{C}$. However, there is substantial RA in all cases except at $800^{\circ} \mathrm{C}$.

6. The ductile fracture patterns are strongly affected by macro delamination cracks formed by extension of the microcracks. However, delamination cracking decreases with increasing temperature.

7. Delamination and corresponding extrinsic factors play a moderate role in NFA-1 strength, and a much stronger role in tensile ductility.

\section{Acknowledgments}

The authors gratefully acknowledge the support received for this research work by the U.S. Department of Energy Office of Fusion Energy Sciences (DE-FG03-94ER54275) and the Office of Nuclear Energy university programs administered by INL (IDNL Award \#00119430 8-442520-59048). 


\section{References}

[1] G. R, Odette, "Recent progress in developing and qualifying nanostructured ferritic alloys for advanced fission and fusion applications", JOM, 66 (2014) 2427-2441.

[2] Ch. Ch. Eiselt, M. Klimenkov, R. Lindau, A. Moslang, G. R. Odette, T. Yamamoto and D. Gragg, "Tensile and fracture toughness properties of the nanostructured oxide dispersion strengthened ferritic alloy $13 \mathrm{Cr}-1 \mathrm{~W}-0.3 \mathrm{Ti}-$ $0.3 \mathrm{Y}_{2} \mathrm{O}_{3}$ ", Journal of Nuclear Materials, 417 (2011) 193-196.

[3] N. J. Cunningham, Y. Wu, A. Etienne, E. M. Haney, G. R. Odette. E. Stergar, D. T. Hoelzer, Y. D. Kim, B. D. Worth and S. A. Maloy, "Effect of bulk oxygen on 14YWT nanostructured ferritic alloys", Journal of Nuclear Materials, 444 (2014) 35-38.

[4] I. S. Kim, B. Y. Choi, C. Y. Kang, T. Okuda, P. J. Maziasz and K. Miyahara, "Effect of $\mathrm{Ti}$ and $\mathrm{W}$ on the mechanical properties and microstructure of $12 \% \mathrm{Cr}$ base mechanical alloyed nano-sized ODS ferritic alloys", ISIJ International, 43 (2003) 1640-1646.

[5] G. R. Odette, M. J. Alinger and B. D. Wirth, "Recent developments in irradiationresistant steels", The Annual Review of Materials Research, 38 (2008) 471-503.

[6] G. R. Odette and D. T. Hoelzer, "Irradiation-tolerant nanostructured ferritic alloys: transforming helium from a liability to an asset”, JOM, 62 (2010) 84-92.

[7] Y. Dai, G. R. Odette and T. Yamamoto, "The effects of helium in irradiated structural alloys." Comprehensive nuclear materials, 1 (2012) 141-193.

[8] M. J. Alinger, G. R. Odette, and G. E. Lucas, “Tensile and fracture toughness properties of MA957: implications to the development of nanocomposited ferritic alloys", Journal of Nuclear Materials, 307-311 (2002) 484-489.

[9] S. A. Maloy, T. A. Saleh, O. Anderoglu, T. J. Romero, G. R. Odette, T. Yamamoto, J. I. Cole and R. Fielding, "Characterization and comparative analysis of the tensile properties of five tempered martensitic steels and an oxide dispersion strengthened ferritic alloy irradiated at $\approx 295^{\circ} \mathrm{C}$ to $\approx 6.5 \mathrm{dpa}$, Journal of Nuclear Materials, 468 (2016) 232-239.

[10] D. T. Hoelzer, K. A. Unocic, E. T. Manneschmidt and M. A. Sokolov, "Reference characterization of the advanced ODS 14YWT-SM12 heat used in HFIR JP30/31 neutron irradiation experiment", Fusion Materials Semiannual Progress Report for Period Ending June 30, 2012, DOE/ER-0313/52, U. S. Department of Energy, 52 (2012) 33-46. 
[11] D. A. McClintock, D. T. Hoelzer, M. A. Sokolov, R. K. Nanstad, “ Mechanical properties of neutron irradiated nanostructured ferritic alloy 14WYT", Journal of Nuclear Materials, 386-388 (2009) 307-311.

[12] T. S. Byun, J. H. Yoon, S. H. Wee, D. T. Hoelzer, and S. A. Maloy, "Fracture behavior of $9 \mathrm{Cr}$ nanostructured ferritic alloy with improved fracture toughness", Journal of Nuclear Materials, 449 (2014) 39-48.

[13] D. T. Hoelzer, J. Bentley, M. A. Sokolov, M. K. Miller, G. R. Odette, M. J. Alinger, "Influence of particle dispersions on the high-temperature strength of ferritic alloys", Journal of Nuclear Materials, 367-370 (2007) 166-172.

[14] M. J. Alinger, G. R. Odette and D. T. Hoelzer, "On the role of alloy composition and processing parameters in nanocluster formation and dispersion strengthening in nanostructured ferritic alloys", Acta Materialia, 57 (2009) 392-406.

[15] J. H. Kim, K. M. Kim, T. S. Byun, D. W. Lee, and C. H. Park, "High-temperature oxidation behavior of nanostructured ferritic oxided dispersion-strengthened alloys", Thermochimical Acta, 579 (2014) 1-8.

[16] P. Miao, G. R. Odette, T. Yamamoto, M. Alinger, D. Hoelzer and D. Gragg, "Effects of consolidation temperature, strength and microstructure on fracture toughness of nanostructured ferritic alloys", Journal of Nuclear Materials, 367370 (2007) 208-212.

[17] N.J. Cunningham, Y. Wu, G.R. Odette, D. Gragg, K. Field, D.T. Hoelzer, S.A. Maloy, "Characterization of the final precursor alloy to a larger best practice heat of 14YWT," Fusion Materials Semiannual Progress Report for Period Ending December 31, 2012, DOE/ER-0313/53, U. S. Department of Energy, 53 (2012) 20-33.

[18] N. J. Cunningham, Y. Wu, G. R. Odette, D. T. Hoelzer, S. A. Maloy, "Characterization of a larger best practice heat of 14YWT in annealed powder, HIP consolidated and extruded forms", Fusion Materials Semiannual Progress Report for Period Ending June 30, 2013, DOE/ER-0313/54, U. S. Department of Energy, 54 (2013) 15-26

[19] M. E. Alam, N. J Cunningham, D. Gragg, K. Fields, G. R. Odette, D. T. Hoelzer and S. A. Maloy, "Mechanical Properties Characterization of a Larger Best Practice Heat of 14YWT NFA1", Fusion Materials Semiannual Progress Report for Period Ending June 30, 2014, DOE/ER-0313/56, U. S. Department of Energy, 56 (2014) 63-69.

[20] S. Pal, M. E. Alam, G. R. Odette, D. Hoelzer and S. Maloy, “ Microstructure, texturing, microcracking and delamination behavior of NFA-1", Fusion Materials Semiannual Progress Report for Period Ending June 30, 2015, DOE/ER-0313/58, U. S. Department of Energy, 58 (2015) 66-82. 
[21] M. E. Alam, S. Pal, D. Gragg, G. R. Odette, D. T. Hoelzer and S. A. Maloy, "Microstructural and Mechanical Behavior of as-fabricated and Annealed 14YWT NFA-1 Alloy", Fusion Materials Semiannual Progress Report for Period Ending December 31, 2015, DOE/ER-0313/59, U. S. Department of Energy, 59 (2015) 35-46.

[22] ASTM E384-11e1, Standard test method for Knoop and Vickers hardness of materials, ASTM International, West Conshohocken, PA, 2011.

[23] H. Je, "Stress corrosion cracking behavior of oxide dispersion strengthened ferritic steel in supercritical pressurized water", $\mathrm{PhD}$ thesis, Kyoto University (2013), p-109.

[24] ASTM E8/E8M-13, Standard test methods for tension testing of metallic materials", ASTM International, West Conshohocken, PA, 2013.

[25] Ch. Ch. Eiselt, M. Klimenkov, R. Lindau and A. Moslang, "Characteristics results and prospects of the 13Cr-1W-0.3Ti-0.3Y2O3 ODS steel", Journal of Nuclear Materials, 386-388 (2009) 525-528.

[26] N. J. Cunningham, "Study of the structure, composition, and stability of Y-Ti-O nm-scale features in nanostructured ferritic alloys", Ph.D thesis, UCSB, 2012.

[27] T. Yamamoto, G. R. Odette and M. A. Sokolov, "On the fracture toughness of irradiated F82H: Effects of loss of constraint and strain hardening capacity", Journal of Nuclear Materials, 417 (2011) 115-119.

[28] R. L. Klueh, J. P. Shingledecker, R. W. Swindeman, and D. T. Hoelzer, “Oxide dispersion-strengthened steels: A comparison of some commercial and experimental alloys", Journal of Nuclear Materials, 341 (2005) 103-114.

[29] J. H. Kim, T. S. Byun, D. T. Hoelzer, S. W. Kim and B. H. Lee, "Temperature dependence of strengthening mechanisms in the nanostructured ferritic alloy 14YWT: Part I-Mechanical and microstructural observations", Materials Science and Engineering A, 559 (2013) 101-110.

[30] J. H. Kim, T. S. Byun, D. T. Hoelzer, C. H. Park, J. T. Yeom and J. K. Hong, "Temperature dependence of strengthening mechanisms in the nanostructured ferritic alloy 14YWT: Part II-Mechanistic models and predictions", Materials Science and Engineering A, 559 (2013) 111-118.

[31] A. Steckmeyer, M. Praud, B. Fournier, J. Malaplate, J. Garnier, J.L. Béchade, I. Tournié, A. Tancray, A. Bougault, and P. Bonnaillie, "Tensile properties and deformation mechanisms of a 14Cr ODS ferritic steel", Journal of Nuclear Materials, 405 (2010) 95-100.

[32] D. J. Srolovitz, R. A. Petkovic-Luton, and M. J. Luton, "Diffusion relaxation of the dislocation-inclusion repulsion", Philosophical Magazine A, 48 (1983) 795 - 
809.

[33] S. Ukai, T. Okuda, M. Fujwara, T. Kobayashi, S. Mizuta and H. Nakashima, "Characterization of high temperature creep properties in recrystallized $12 \mathrm{Cr}$ ODS ferritic steel claddings", Journal of Nuclear Science and technology, 39 (2002) 872-879.

[34] T. S. Byun, D. T. Hoelzer, G. R. Romanosky, and D. A. McClintock, "Thermochemical behavior of nanostructured ODS alloys", ICFRM-14 Conference (2009) Sapporo, Japan.

[35] G. Zhang, Z. Zhou, M. Wang, S. Li, L. Zou and L. Zhang, "Tensile and Charpy impact properties of an ODS ferritic/martensitic steel $9 \mathrm{Cr}-1.8 \mathrm{~W}-0.5 \mathrm{Ti}-0.35 \mathrm{Y}_{2} \mathrm{O}_{3}$ ", Fusion Engineering and Design, 89 (2014) 280-283. 


\section{Figure Captions}

Fig. 1 (a) NFA-1 plate section views and tensile specimen orientations with respect to the extrusion, cross rolling and thickness directions; and, (b) the dimensions of the SSJ2 dogbone tensile specimen.

Fig. 2 NFA-1 microstructures for various plate sections: (a) SEM at lower magnification; (b) SEM/FIB at higher magnification. Figs. 2c and d show the corresponding distribution of grain size, and aspect ratio, respectively.

Fig. 3 (a) EBSD IPF map and intensity projection (bottom right insert) for the plate side section (LS) show a strong <110> fiber texture in the extrusion direction; and, (b) a TEM micrograph shows the microcrack tip and associated dislocation structure.

Fig. 4 Engineering stress-strain curves as a function of temperature and orientation for: (a) LT and TL; and, (b) LS and TS.

Fig. 5 NFA-1 strength and ductility as a function of temperature for: (a) the $0.2 \%$ yield stress, $\mathrm{s}_{\mathrm{y}}$; (b) the ultimate tensile stress, $\mathrm{s}_{\mathrm{u}}$; (c) uniform elongation, $\mathrm{e}_{\mathrm{u}}$; and, (d) total elongation, $e_{t}$.

Fig. 6 True stress-true plastic strain curves as a function of temperature and orientation for: (a) LT and TL; and, (b) LS and TS.

Fig. 7 Images of NFA-1 tensile specimens tested at ambient temperature: (a-b) low magnification macro views of a fracture surface; (c-d) macro (insert) and higher magnification views of a tensile specimen side surface, marked by the boxed; (e-f) schematic of the microcracks in the two orientations; and, (g-h) high magnification images of ductile fracture surfaces for LT and TL, as well as LS and TS, orientations. Note that all the inserted macro-views show the length (horizontal direction), and width (vertical direction), as well as the fractured edge, of the tensile specimen.

Fig. 8 The $0.2 \%$ yield strength of various NFA steels as a function of temperature compared to NFA-1 [1, 4, 5, 10, 11, 13,17, 28, 29, 34-35].

Fig. 9 Images of NFA-1 LT (left) and LS (right) tensile specimens tested at $200^{\circ} \mathrm{C}$ showing: (a-b) macro views of a fracture surface; (c-d) macro (insert) and higher magnification views of a tensile specimen side surface; and, (e-f) high magnification images of ductile fracture surfaces. See text for a discussion.

Fig. 10 Images of NFA-1 LT (left) and LS (right) tensile specimens tested at $400^{\circ} \mathrm{C}$ showing: (a-b) macro views of a fracture surface; (c-d) macro (insert) and higher magnification views of a tensile specimen side surface; and (e-f) high magnification images of ductile fracture surfaces. See text for a discussion.

Fig. 11 Images of NFA-1 LT and TL (left), and LS and TS (right) tensile specimens tested at $600^{\circ} \mathrm{C}$ showing: (a-b) macro views of a fracture surface; (c-d) macro (insert) and higher magnification views of a tensile specimen side surface; and (e-f) high magnification images of ductile fracture surfaces. See text for a discussion.

Fig. 12 Images of NFA-1 LT (left) and LS (right) tensile specimens tested at $800^{\circ} \mathrm{C}$ showing: (a-b) macro views of a fracture surface; (c-d) macro (insert) and higher magnification views of a tensile specimen side surface; and (e-f) high magnification images of ductile fracture surfaces. See text for a discussion. 


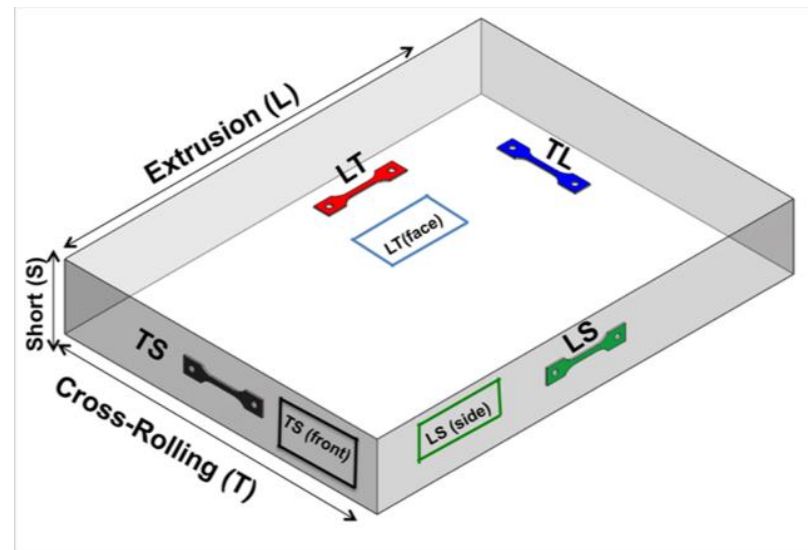

(a)

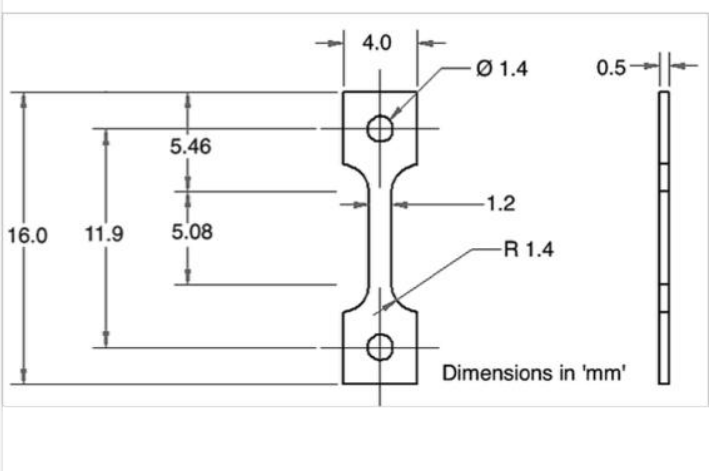

(b)

Fig. 1 (a) NFA-1 plate section views and tensile specimen orientations with respect to the extrusion, cross rolling and thickness directions; and, (b) the dimensions of the SSJ2 dogbone tensile specimen. 

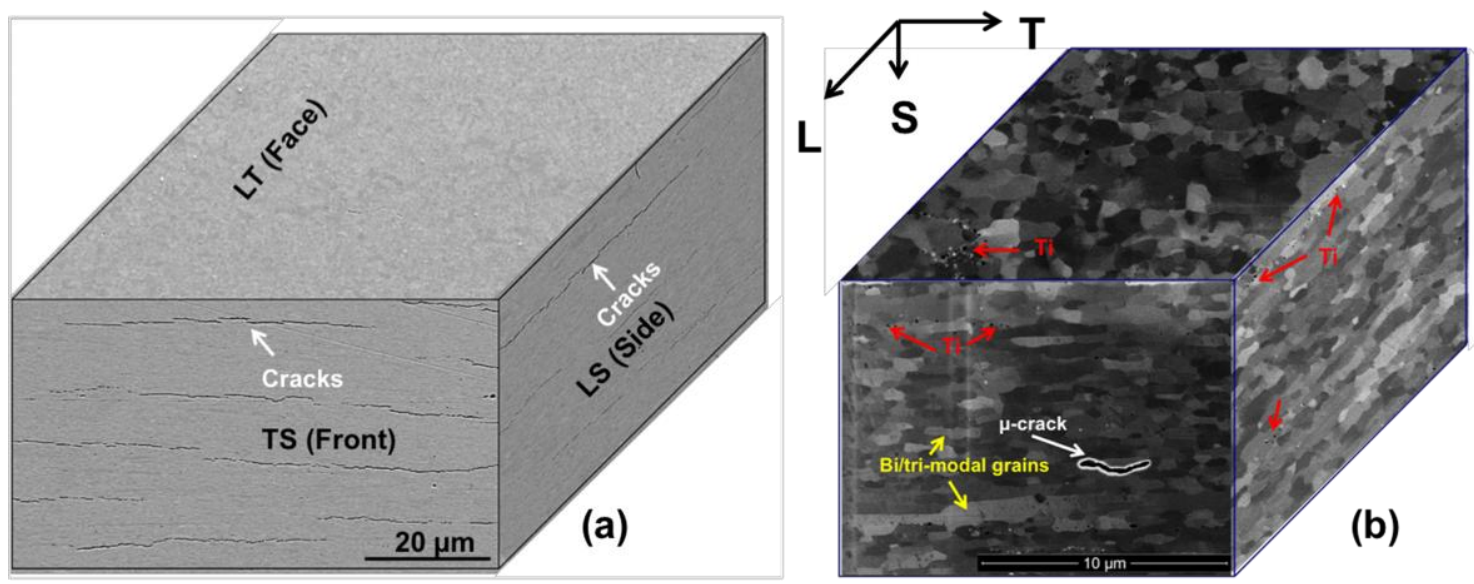

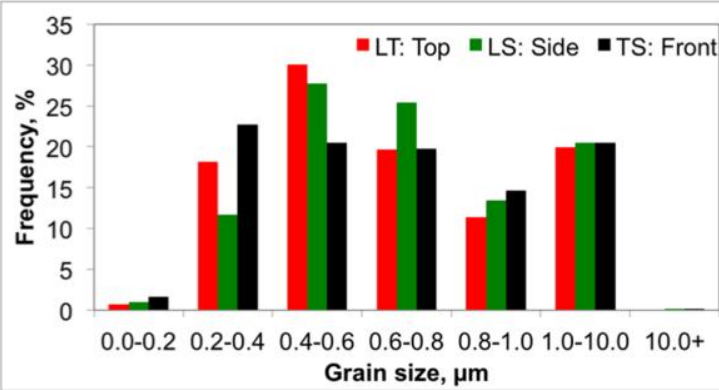

(c)

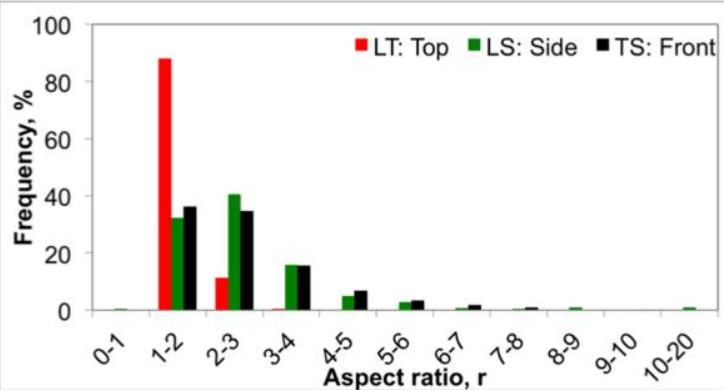

(d)

Fig. 2 NFA-1 microstructures for various plate sections: (a) SEM at lower magnification; (b) SEM/FIB at higher magnification. Figs. 2c and d show the corresponding distribution of grain size, and aspect ratio, respectively. 


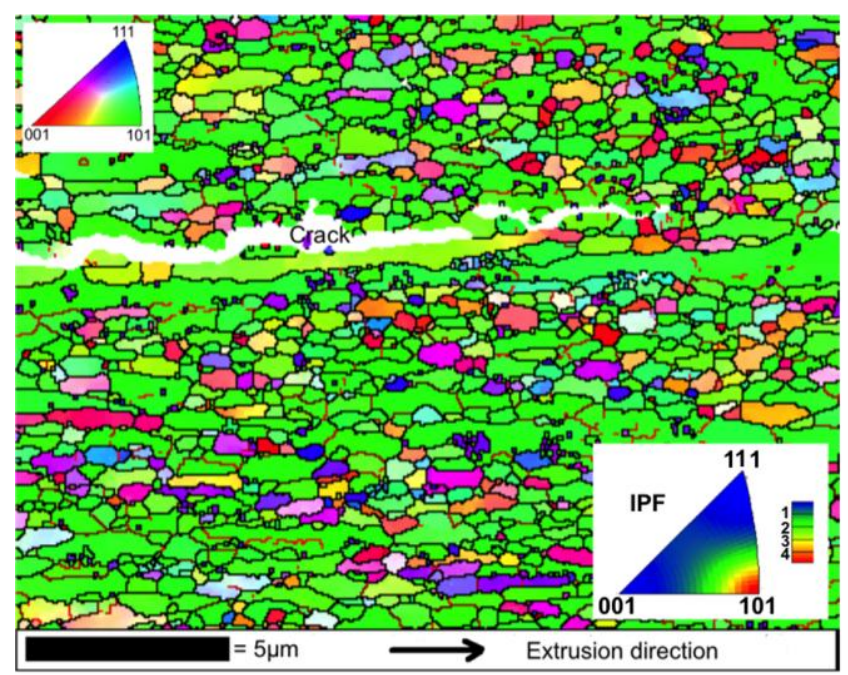

(a)

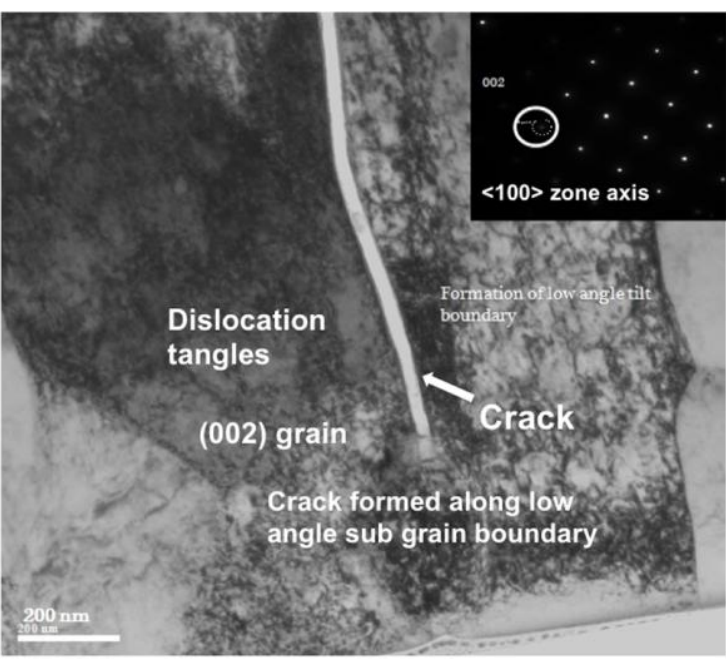

(b)

Fig. 3 (a) EBSD IPF map and intensity projection (bottom right insert) for the plate side section (LS) show a strong $\langle 110\rangle$ fiber texture in the extrusion direction; and, (b) a TEM micrograph shows the microcrack tip and associated dislocation structure. 

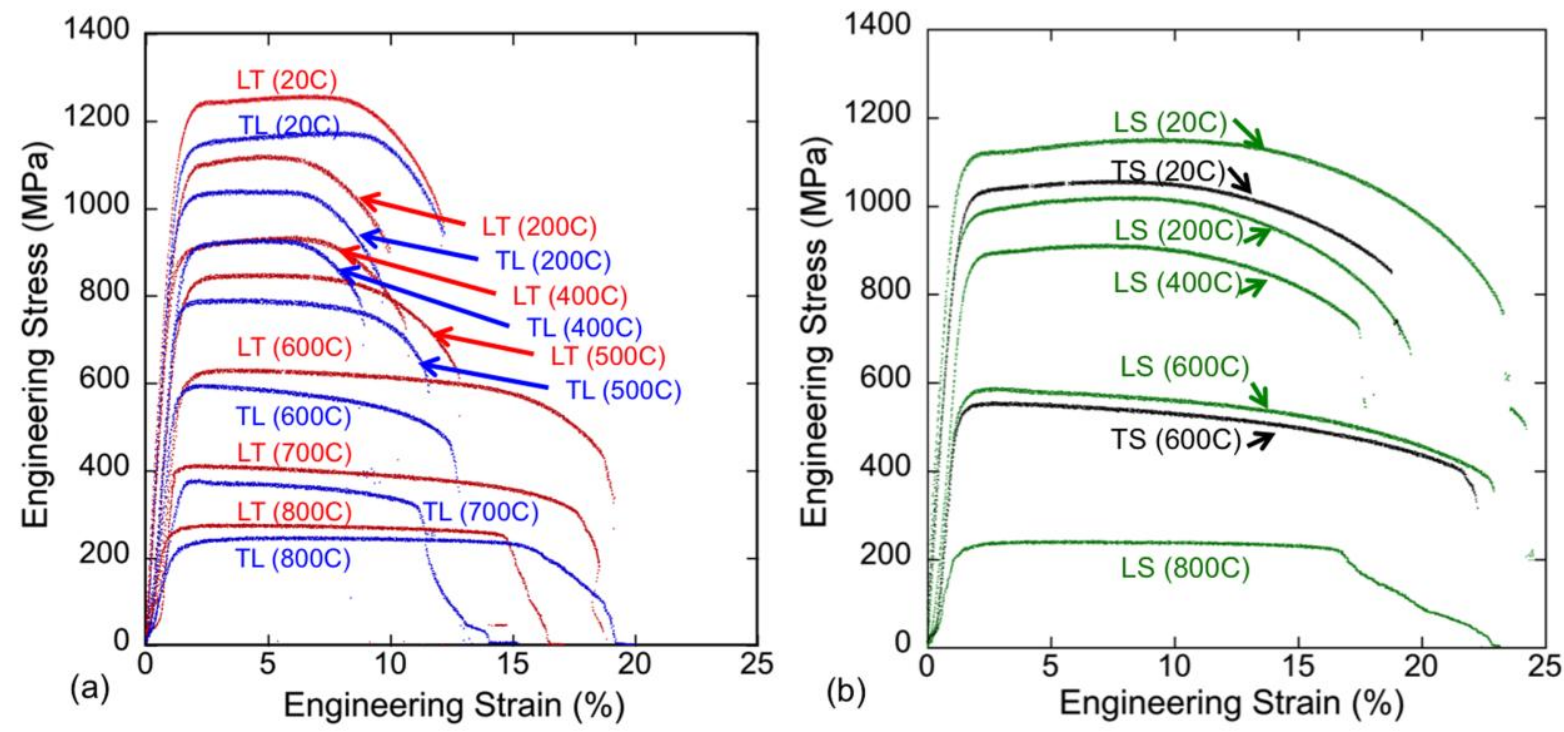

Fig. 4 Engineering stress-strain curves as a function of temperature and orientation for: (a) LT and TL; and, (b) LS and TS. 

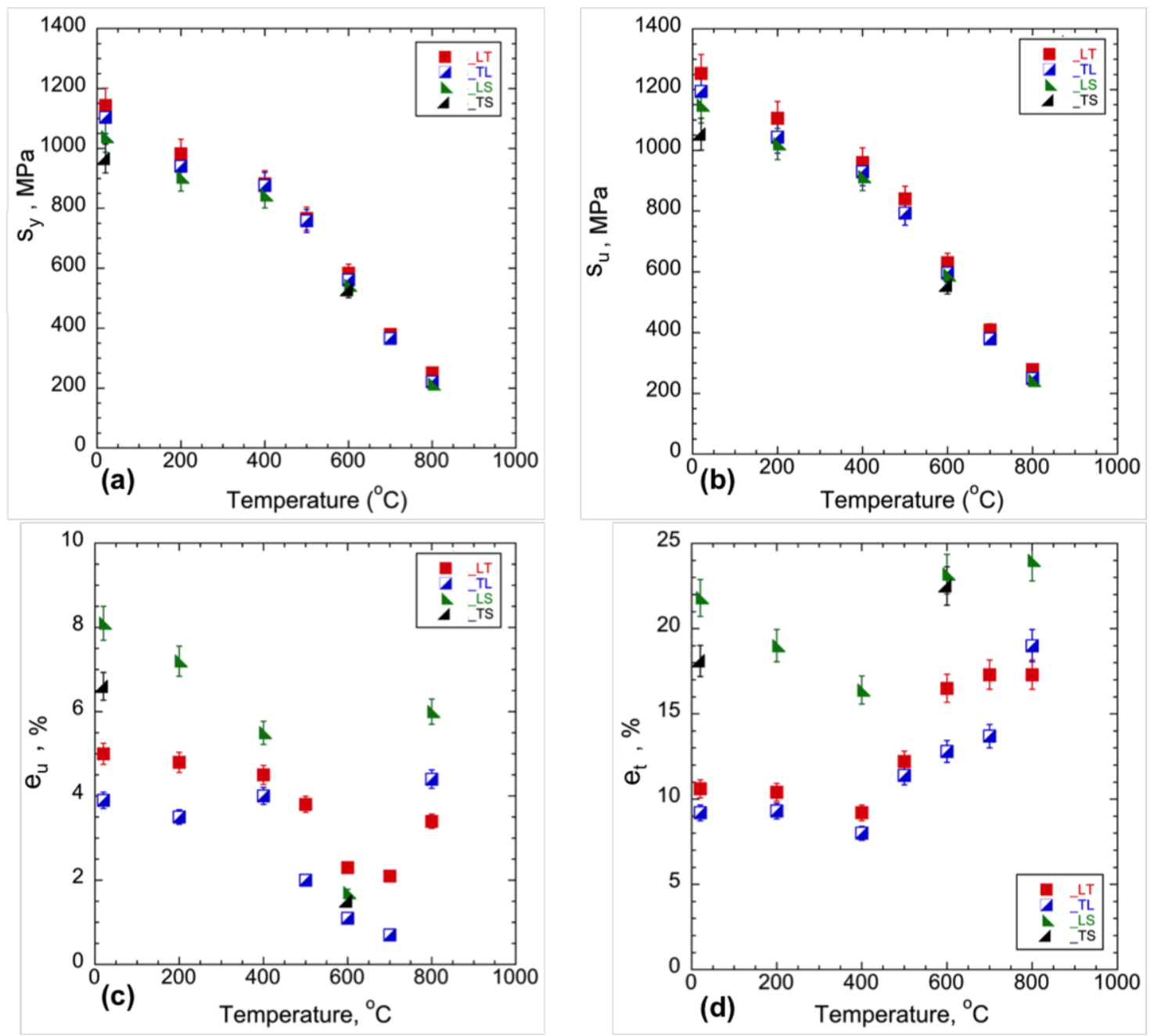

Fig. 5 NFA-1 strength and ductility as a function of temperature for: (a) the $0.2 \%$ yield stress, $\mathrm{s}_{\mathrm{y}}$; (b) the ultimate tensile stress, $\mathrm{s}_{\mathrm{u}}$; (c) uniform elongation, $\mathrm{e}_{\mathrm{u}}$; and, (d) total elongation, $e_{t}$. 

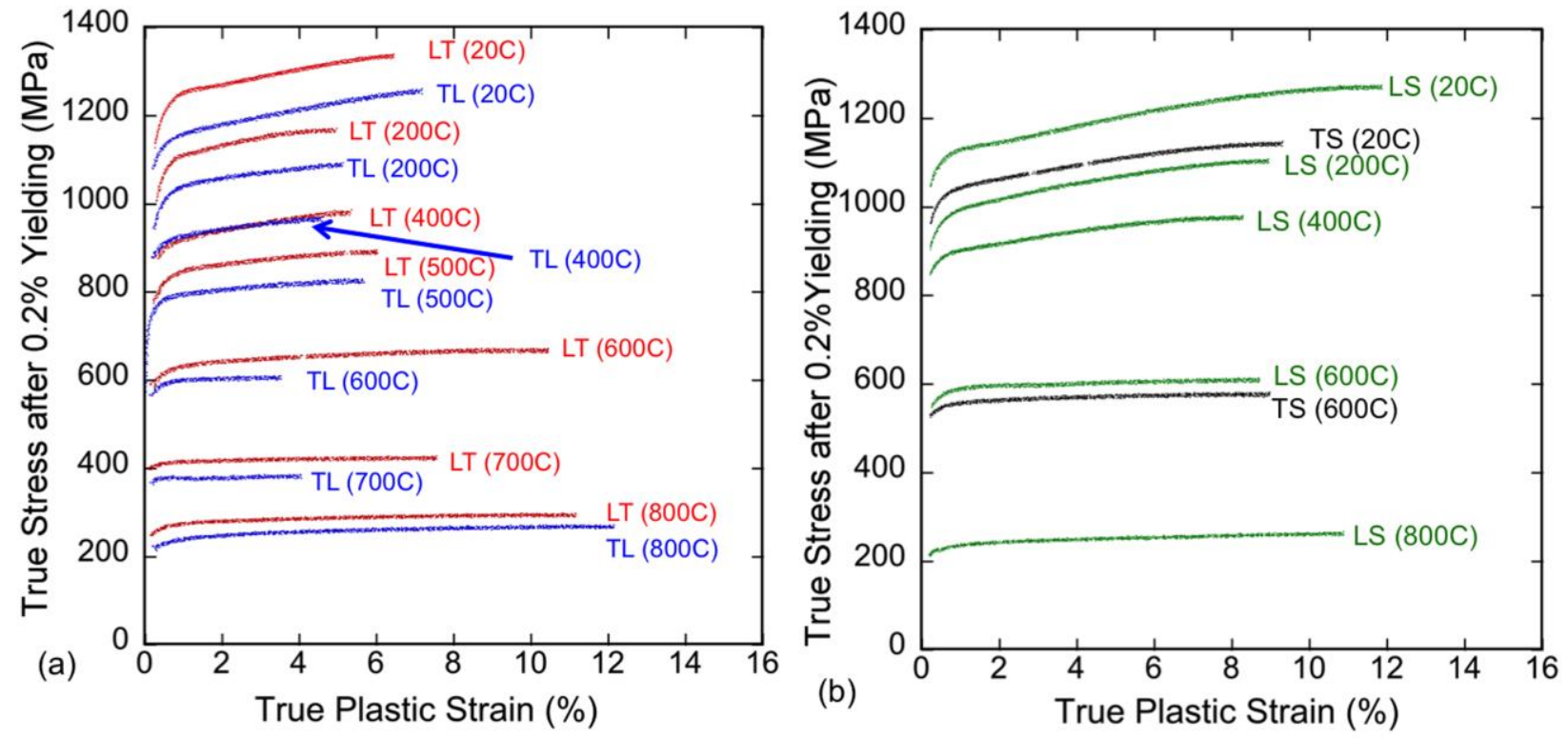

Fig. 6 True stress-true plastic strain curves as a function of temperature and orientation for: (a) LT and TL; and (b) LS and TS. 

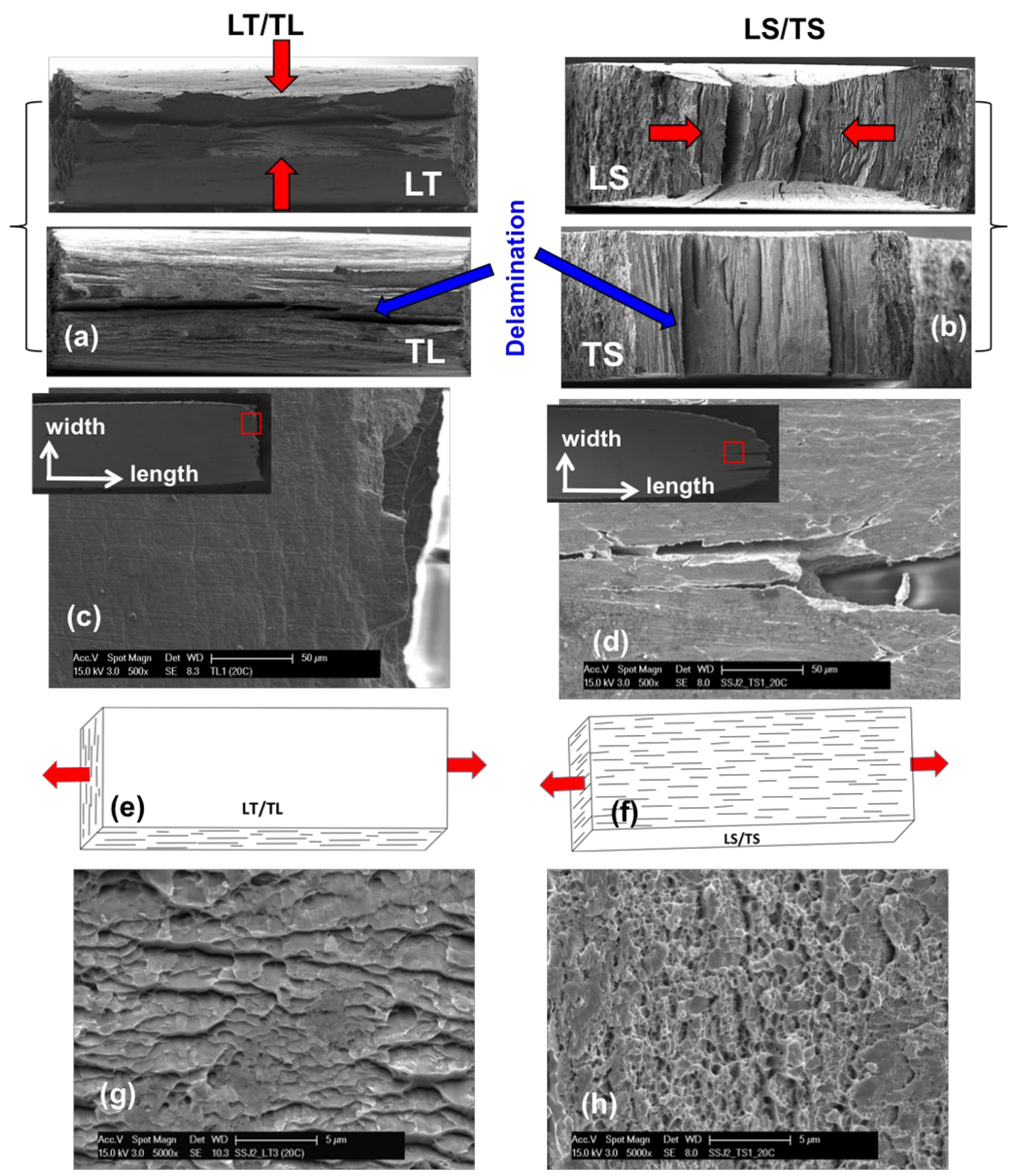

Fig. 7 Images of NFA-1 tensile specimens tested at ambient temperature: (a-b) macro-views of a fracture surface; (c-d) macro (insert) and higher magnification view of a tensile specimen side surface, marked as boxed; (ef) schematic of the microcracks in the two orientations; and ( $g-h)$ high magnification images of ductile fracture surfaces for LT and TL as well as LS and TS. Note that all the inserted macro-views show the length (horizontal direction), and width (vertical direction), as well as the fractured edge, of the tensile specimen. 


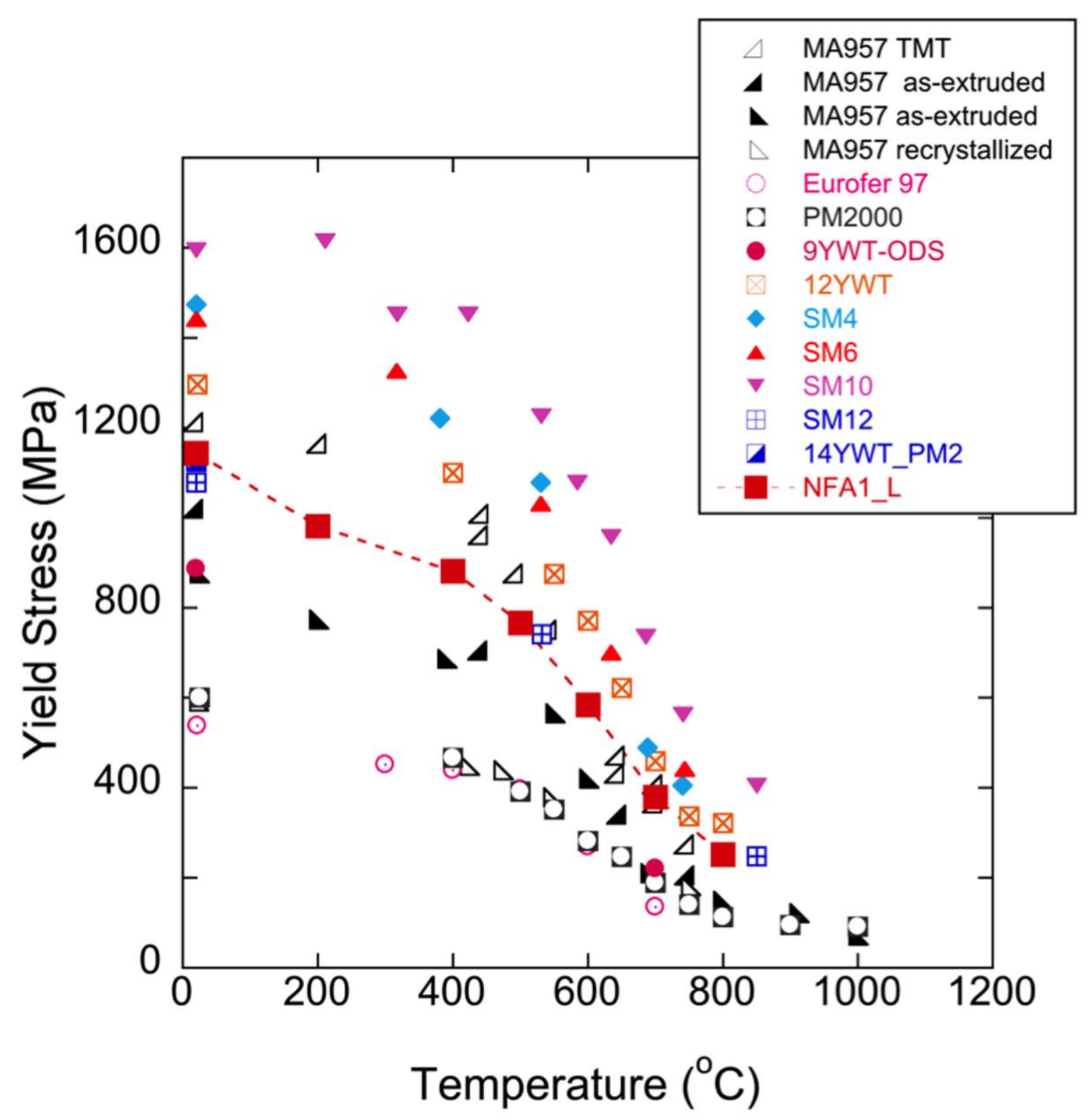

Fig. 8 The $0.2 \%$ yield strength of various NFA steels as a function of temperature along with NFA-1 [1, 4, 5, 10, 11, 13,17, 28, 29, 34-35]. 
LT
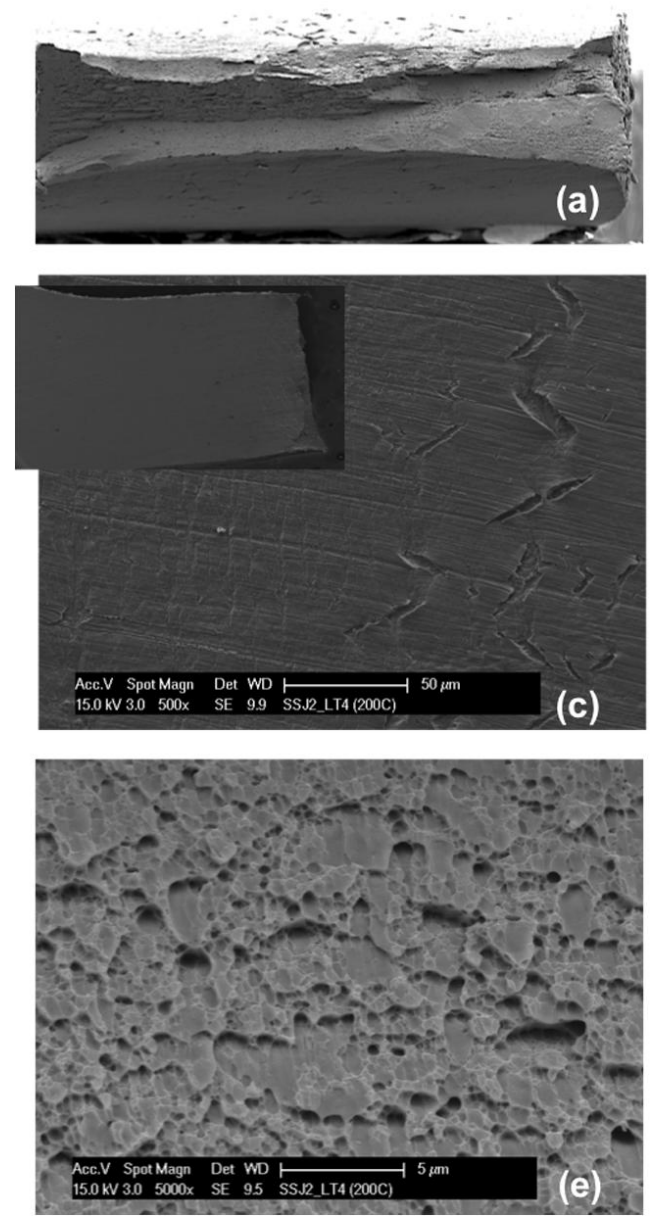

LS
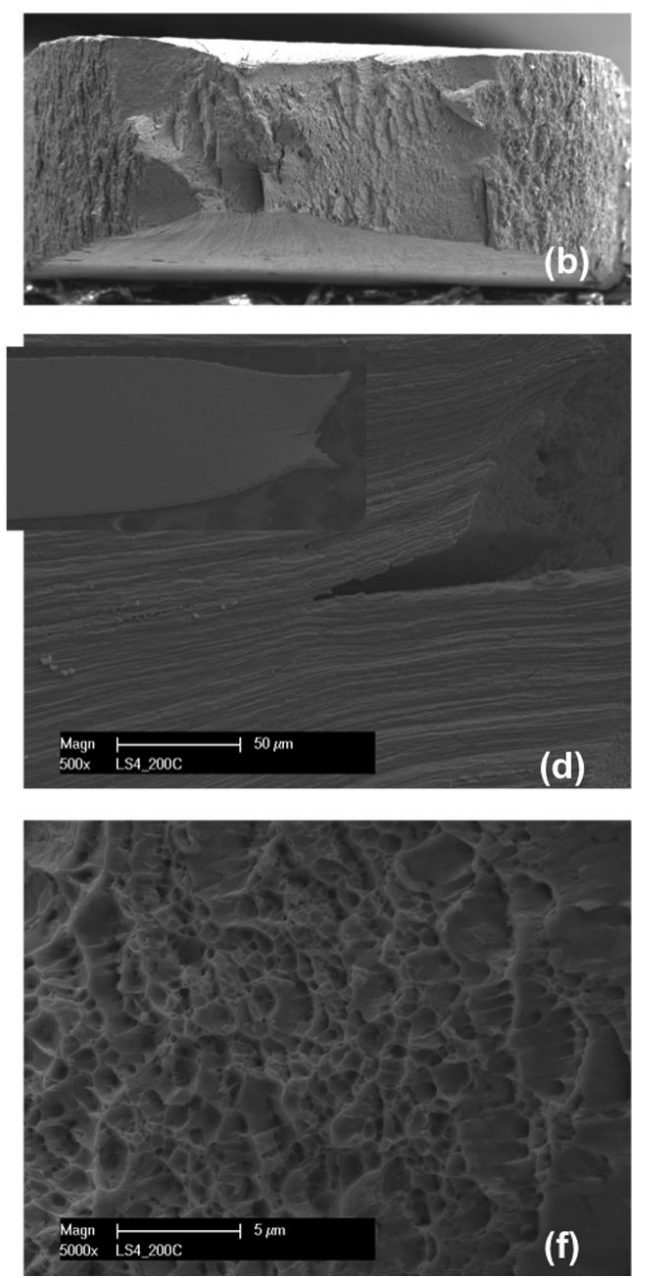

Fig. 9 Images of NFA-1 LT (left) and LS (right) tensile specimens tested at $200^{\circ} \mathrm{C}$ showing: (a-b) macro-views of a fracture surface; (c-d) macro (insert) and higher magnification view of a tensile specimen side surface; and (e-f) high magnification images of ductile fracture surfaces. See text for a discussion. 
LT
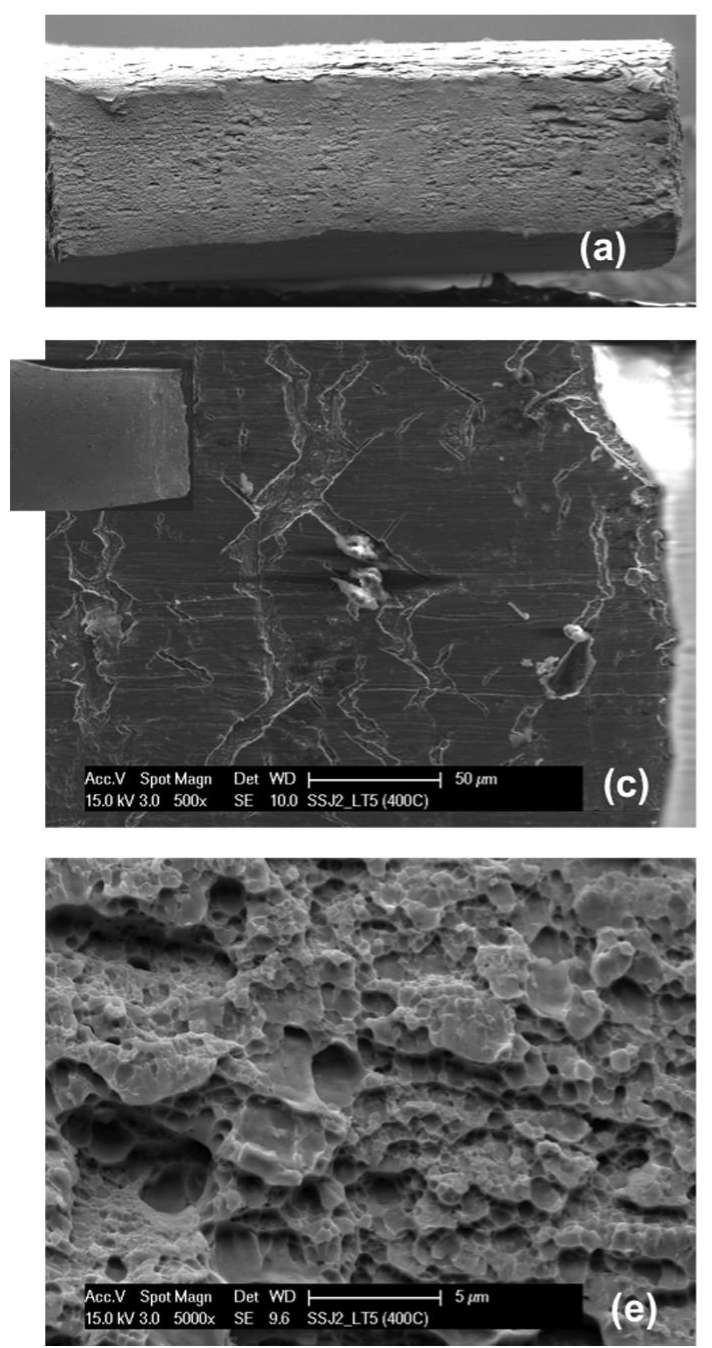

LS
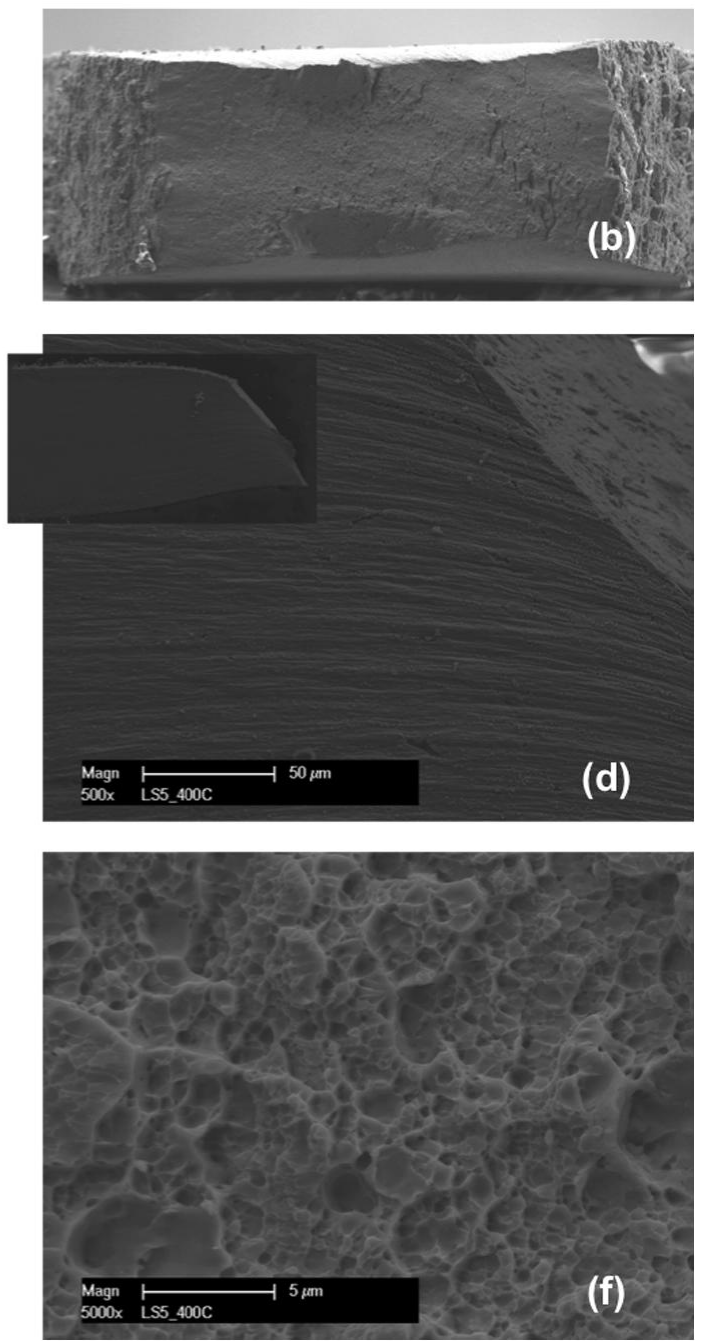

Fig. 10 Images of NFA-1 LT (left) and LS (right) tensile specimens tested at $400^{\circ} \mathrm{C}$ showing: (a-b) macro-views of a fracture surface; (c-d) macro (insert) and higher magnification view of a tensile specimen side surface; and (e-f) high magnification images of ductile fracture surfaces. See text for a discussion. 


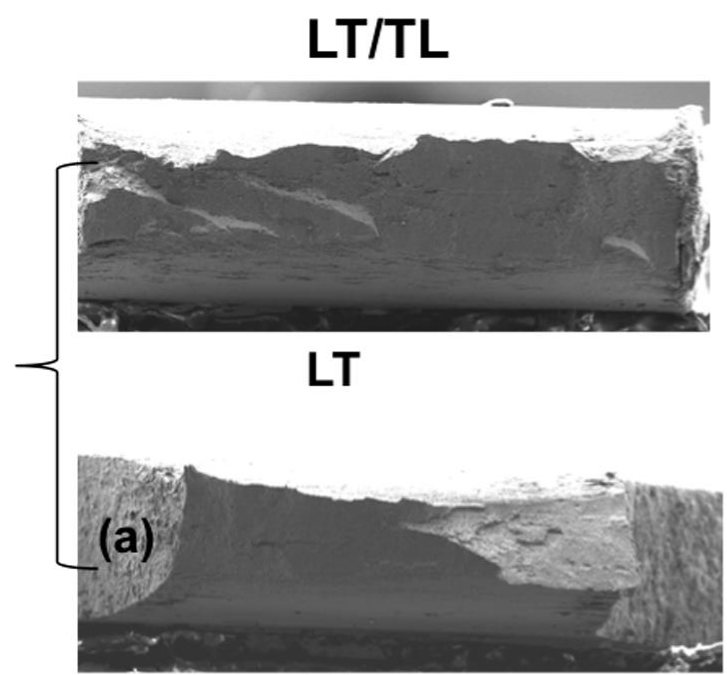

TL
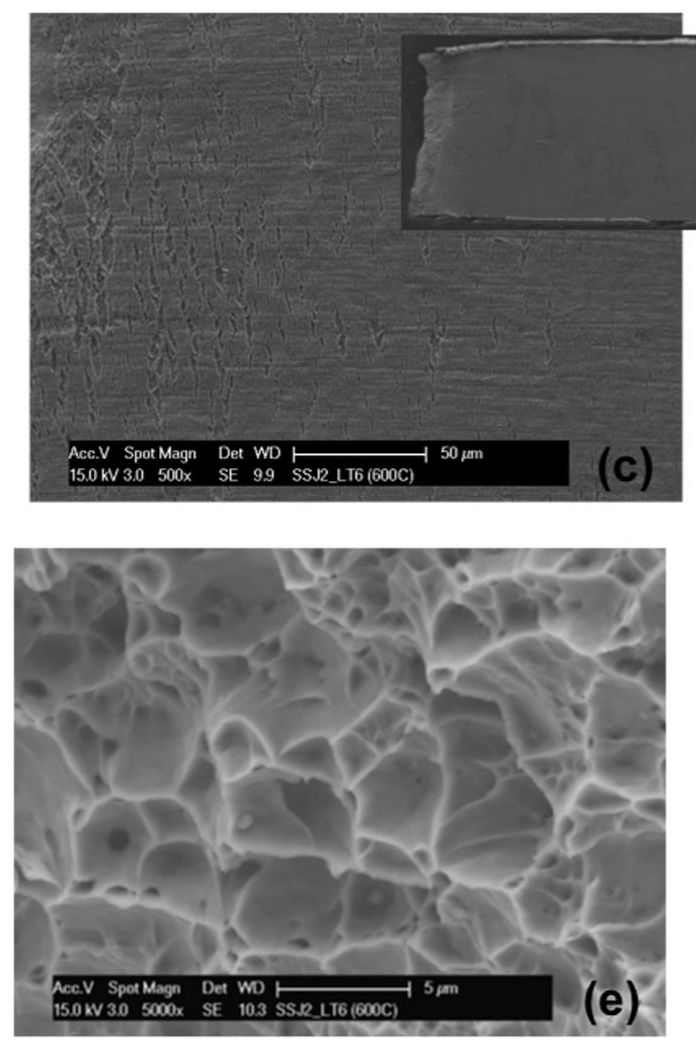

\section{LS/TS}

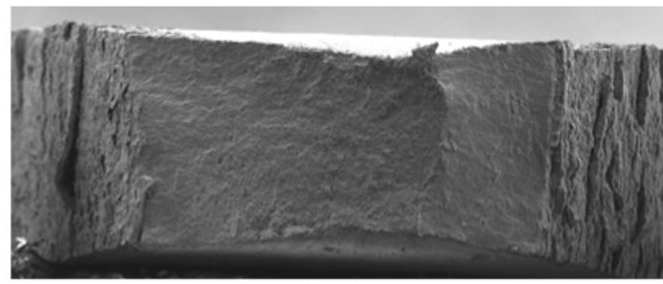

LS

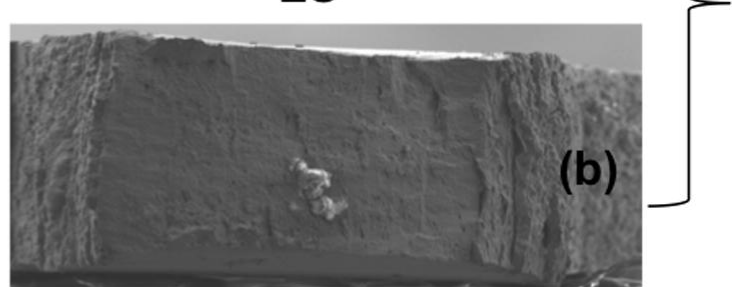

TS
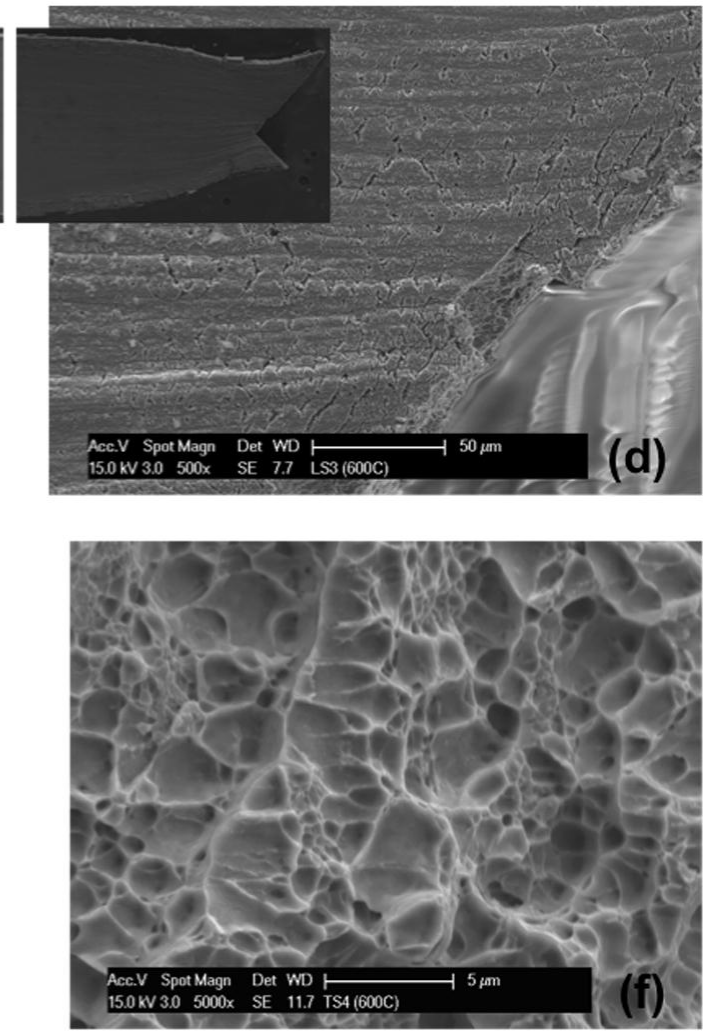

Fig. 11 Images of NFA-1 LT and TL (left), and LS and TS (right) tensile specimens tested at $600^{\circ} \mathrm{C}$ showing: (a-b) macro-views of a fracture surface; (c-d) macro (insert) and higher magnification view of a tensile specimen side surface; and (e-f) high magnification images of ductile fracture surfaces. See text for a discussion. 
LT
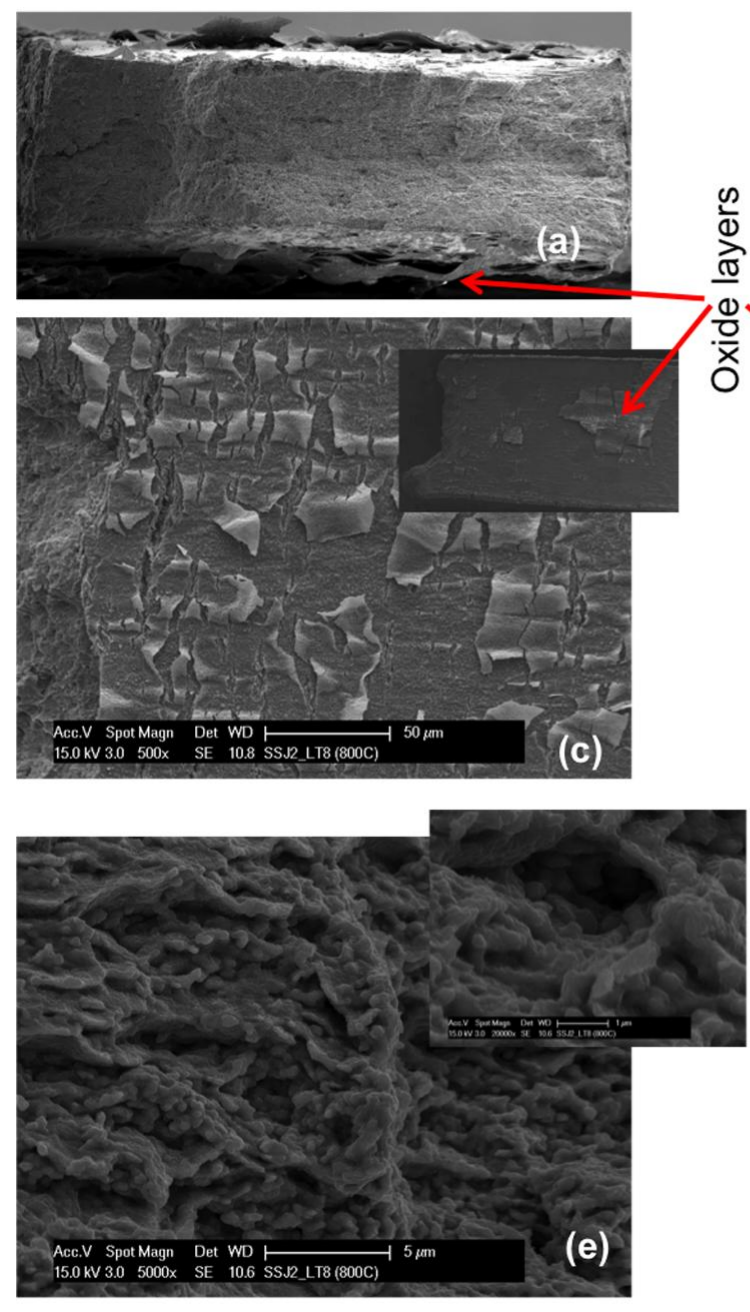

LS

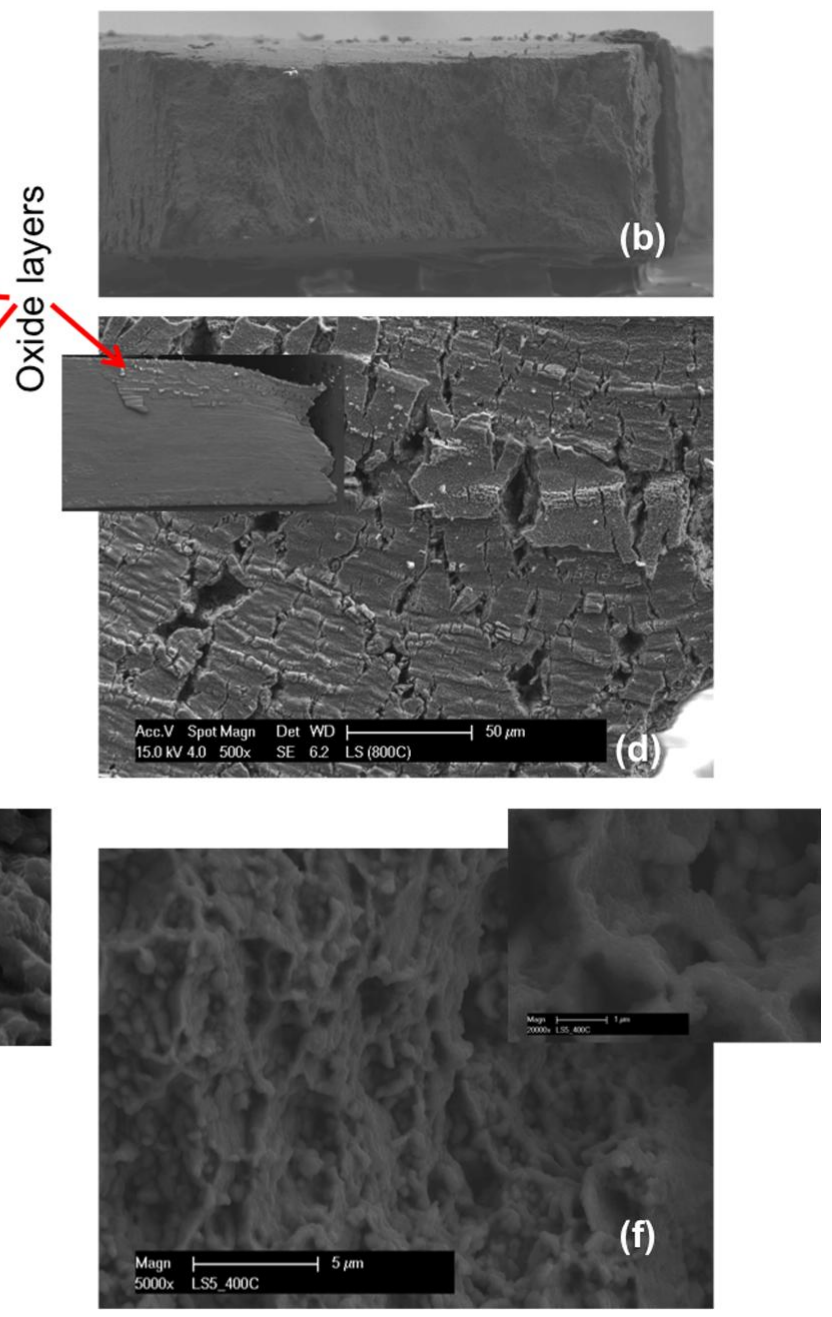

Fig. 12 Images of NFA-1 LT (left) and LS (right) tensile specimens tested at $800^{\circ} \mathrm{C}$ showing: (a-b) macro-views of a fracture surface; (c-d) macro (insert) and higher magnification view of a tensile specimen side surface; and (e-f) high magnification images of ductile fracture surfaces. See text for a discussion. 


\section{List of Tables}

Table 1 Grain morphology and microhardness of FCRD NFA-1 for the different plate sections.

Table 2 The average size, grain aspect ratio, number and area fractions of grains for different section views of the NFA-1 plate.

Table 3 A tabulation of the tensile properties of NFA-1 as a function of temperatures and orientation. 
Table 1 Grain morphology and microhardness of FCRD NFA-1 for the different plate sections.

\begin{tabular}{|c|c|c|c|c|c|}
\hline Planes & $\begin{array}{c}\text { Long, l } \\
(\mu \mathrm{m})\end{array}$ & $\begin{array}{c}\text { Short, } \mathrm{s} \\
(\mu \mathrm{m})\end{array}$ & $\begin{array}{c}\text { Av, d= } \\
(\mathbf{l}+\mathbf{s}) / 2 \\
(\mu \mathrm{m})\end{array}$ & $\begin{array}{c}\text { Aspect } \\
\text { ratio }\end{array}$ & $\begin{array}{c}\text { Microhardness, } \\
\mathbf{H}_{\mathrm{v}},\left(\mathrm{Kg} / \mathbf{m m}^{2}\right)\end{array}$ \\
\hline $\begin{array}{c}\text { LT } \\
\text { (Face) }\end{array}$ & $\begin{array}{c}0.767 \pm \\
0.566\end{array}$ & $\begin{array}{c}0.517 \pm \\
0.355\end{array}$ & $\begin{array}{c}0.642 \pm \\
0.450\end{array}$ & $1.5 \pm 0.4$ & $376 \pm 18$ \\
\hline LS (Side) & $\begin{array}{c}0.792 \pm \\
0.638\end{array}$ & $\begin{array}{c}0.301 \pm \\
0.108\end{array}$ & $\begin{array}{c}0.546 \pm \\
0.343\end{array}$ & $2.7 \pm 1.6$ & $368 \pm 25$ \\
\hline $\begin{array}{c}\text { TS } \\
\text { (Front) }\end{array}$ & $\begin{array}{c}0.799 \pm \\
0.833\end{array}$ & $\begin{array}{c}0.296 \pm \\
0.180\end{array}$ & $\begin{array}{c}0.548 \pm \\
0.482\end{array}$ & $2.7 \pm 1.3$ & $352 \pm 39$ \\
\hline
\end{tabular}

Table 2 The average size, grain aspect ratio, number and area fractions of grains for different section views of the NFA-1 plate.

\begin{tabular}{cccccc}
\hline Planes & $\begin{array}{c}\text { Range } \\
(\boldsymbol{\mu m})\end{array}$ & $\begin{array}{c}\text { Length, I } \\
(\boldsymbol{\mu \mathbf { m } )}\end{array}$ & $\begin{array}{c}\text { Aspect } \\
\text { ratio, } \mathbf{r}\end{array}$ & $\begin{array}{c}\text { No. freq. of } \\
\text { grains, (\%) }\end{array}$ & $\begin{array}{c}\text { Area } \\
\text { fraction, } \\
(\boldsymbol{\%})\end{array}$ \\
\hline \multirow{3}{*}{ LT (Face) } & $0-1$ & $0.57 \pm 0.20$ & $1.5 \pm 0.4$ & 80 & 60 \\
& $1-10$ & $1.57 \pm 0.80$ & $1.6 \pm 0.4$ & 20 & 40 \\
& $10+$ & - & - & - & - \\
\hline \multirow{2}{*}{ LS (Side) } & $0-1$ & $0.60 \pm 0.19$ & $2.2 \pm 0.7$ & 79.3 & 64.6 \\
& $1-10$ & $1.42 \pm 0.50$ & $4.5 \pm 2.0$ & 20.5 & 33.2 \\
& $10+$ & 11.3 & 15.8 & 0.2 & 2.2 \\
\hline \multirow{3}{*}{ TS (Front) } & $0-1$ & $0.56 \pm 0.22$ & $2.2 \pm 0.9$ & 79.3 & 59.5 \\
& $1-10$ & $1.59 \pm 0.94$ & $4.1 \pm 1.5$ & 20.5 & 37.9 \\
& $10+$ & 12.94 & 10.0 & 0.2 & 2.6 \\
\hline
\end{tabular}


Table 3 A tabulation of the tensile properties of NFA-1 as a function of temperatures and orientation.

\begin{tabular}{|c|c|c|c|c|c|c|}
\hline $\begin{array}{c}\text { Temp. } \\
\left({ }^{0} \mathrm{C}\right)\end{array}$ & Orientations & $\begin{array}{c}\mathbf{S}_{\mathbf{y}} \\
(\mathbf{M P a})\end{array}$ & $\begin{array}{c}\mathbf{S}_{\mathbf{u}} \\
(\mathbf{M P a})\end{array}$ & $\begin{array}{c}\mathbf{e}_{\mathbf{u}} \\
(\%)\end{array}$ & $\begin{array}{c}e_{t} \\
(\%)\end{array}$ & $\begin{array}{l}\text { RA } \\
(\%)\end{array}$ \\
\hline \multirow{4}{*}{20} & $\mathrm{LT}$ & $1144 \pm 21$ & $1253 \pm 25$ & $5.0 \pm 1.5$ & $10.6 \pm 2.0$ & $52 \pm 2$ \\
\hline & $\mathrm{TL}$ & $1102 \pm 6$ & $1175 \pm 1$ & $3.9 \pm 0.2$ & $8.4 \pm 1.4$ & $51 \pm 3$ \\
\hline & LS & $1039 \pm 6$ & $1148 \pm 7$ & $8.1 \pm 0.1$ & $21.8 \pm 1.5$ & $74 \pm 13$ \\
\hline & $\mathrm{TS}$ & $966 \pm 6$ & $1053 \pm 4$ & $6.6 \pm 0.1$ & $18.1 \pm 0.8$ & $71 \pm 6$ \\
\hline \multirow{3}{*}{200} & $\mathrm{LT}$ & $982 \pm 25$ & $1106 \pm 21$ & $4.8 \pm 1.5$ & $10.4 \pm 1.5$ & $56 \pm 2$ \\
\hline & $\mathrm{TL}$ & 940 & 1043 & 3.5 & 9.3 & 54 \\
\hline & LS & 903 & 1021 & 7.2 & 19 & 57 \\
\hline \multirow{3}{*}{400} & $\mathrm{LT}$ & $882 \pm 21$ & $960 \pm 34$ & $4.5 \pm 1.3$ & $9.2 \pm 1.7$ & 49 \\
\hline & $\mathrm{TL}$ & 876 & 930 & 4.0 & 8.0 & 50 \\
\hline & LS & 844 & 913 & 5.5 & 16.4 & 47 \\
\hline \multirow{2}{*}{500} & $\mathrm{LT}$ & $766 \pm 14$ & $840 \pm 14$ & $3.8 \pm 0.3$ & $12.2 \pm 0.7$ & 51 \\
\hline & $\mathrm{TL}$ & 758 & 793 & 2.0 & 11.4 & 42 \\
\hline \multirow{4}{*}{600} & $\mathrm{LT}$ & $584 \pm 35$ & $630 \pm 35$ & $2.3 \pm 0.1$ & $16.5 \pm 3.9$ & 62 \\
\hline & $\mathrm{TL}$ & 561 & 596 & 1.1 & 12.8 & 49 \\
\hline & LS & 543 & 589 & 1.7 & 23.2 & 51 \\
\hline & $\mathrm{TS}$ & 528 & 555 & 1.5 & 22.5 & 46 \\
\hline \multirow{2}{*}{700} & $\mathrm{LT}$ & $379 \pm 2$ & $409 \pm 6$ & $2.1 \pm 0.7$ & $17.3 \pm 2.4$ & 31 \\
\hline & $\mathrm{TL}$ & 366 & 379 & 0.7 & 13.7 & 35 \\
\hline \multirow{3}{*}{800} & $\mathrm{LT}$ & $251 \pm 6$ & $278 \pm 1$ & $3.4 \pm 0.0$ & $17.3 \pm 0.4$ & 30 \\
\hline & $\mathrm{TL}$ & 221 & 249 & 4.4 & 19.0 & 31 \\
\hline & LS & 213 & 242 & 6 & 24 & 42 \\
\hline
\end{tabular}

$\mathrm{s}_{\mathrm{y}}=$ yield stress, $\mathrm{s}_{\mathrm{u}}=$ ultimate tensile stress, $\mathrm{e}_{\mathrm{u}}=$ uniform elongation, $\mathrm{e}_{\mathbf{t}}=$ total elongation, and RA $=$ reduction of area. 